\title{
Oral delivery strategies for nutraceuticals: delivery vehicles and absorption enhancers
}

John P. Gleeson, Sinéad M. Ryan and David J. Brayden

UCD School of Veterinary Medicine and UCD Conway Institute, University College Dublin, Belfield, Dublin 4, Ireland

\section{Background}

Lifestyle issues contribute to the development of obesity, type 2 diabetes, and cardiovascular disease. Together with appropriate diet and exercise, nutraceuticals may contribute to managing prevention at an early stage prior to therapeutic intervention. However, many useful food-derived bioactive compounds will not sufficiently permeate the small intestine to yield efficacy without appropriate oral delivery technology. The pharmaceutical industry uses commercialised approaches for oral delivery including solubilizing technologies for small molecules, which could be applied to selected nutraceuticals with solubility issues. Systems currently being studied for labile and poorly permeable hydrophilic peptides and macromolecules include nanoparticles, intestinal permeation enhancers (PE) and mucolytics. These may also have potential for application to nutraceuticals with similar suboptimal physicochemical characteristics.

\section{Scope and Approach}

We introduce factors which effect oral delivery of four types of nutraceuticals, namely fatty acids, bioactive peptides, micronutrients, and phytochemicals. Factors preventing oral absorption can arise from molecule physicochemical characteristics, which influence solubility, stability, and epithelial permeability in the gastrointestinal tract (GIT). We highlight the potential of selected delivery strategies to improve oral bioavailability of different types of nutraceuticals.

\section{Key Findings and Conclusions}

There is an opportunity for the nutraceutical industry to leverage the pharmaceutical industry's progress in oral drug delivery. The use of delivery approaches using formulation with excipients or substances with a history of use in man has potential to improve solubility, stability, or permeability of nutraceuticals, leading to improved oral bioavailability. 
Leveraging oral delivery formulation approaches across nutraceutical and pharmaceutical molecules will lead to synergies for both fields.

Key words: Nutraceuticals; food-derived bioactives; oral delivery; nanoparticles; intestinal permeation enhancers; oral bioavailability. 


\section{Introduction}

With growing prevalence of lifestyle-associated diseases, including obesity, Type II diabetes and cardiovascular disease, there is a need to reduce risks of onset of these diseases (Menotti $\&$ Puddu, 2015). Nutraceuticals are defined as isolated food-derived bioactive molecules, which provide physiological benefits beyond basic nutrition (Pan, Lai, Dushenkov, \& Ho, 2009). Recently, research has focused on such bioactives with anti-oxidative, antiinflammatory, anti-hyperlipidemic and anti-hypertensive activities. However, there are many hurdles to overcome for the oral delivery of nutraceuticals depending on the bioactive's physicochemical properties. The molecule may be prone to sub-optimal release and dispersion from the delivery dosage form and/or low solubility in small intestinal fluids (bioacessibility), $\mathrm{pH}$ - and enzymatic degradation, biotransformation during gastrointestinal transit, poor diffusion across mucus and low intestinal epithelial permeability; all of which must be overcome prior to absorption into the bloodstream (Braithwaite, et al., 2014; McClements, Decker, Park, \& Weiss, 2009). Without appropriate delivery systems, current nutraceuticals with such characteristics are unlikely to provide the intended physiological effect, despite marketing claims to the contrary.

The pharmaceutical industry has examined microbes and plants as sources of drug discovery molecules, examples being penicillin (Penicillium species), colchicine (autumn crocus), acetyl salicylic acid (willow tree bark), and paclitaxel (pacific yew tree) (Dias, Urban, \& Roessner, 2012). There is now additional focus on food as a new source of bioactives. With the growing consumer market for nutraceuticals, there is scope for the nutraceutical industry to leverage innovative research from the pharmaceutical industry in delivering poorly soluble and poorly absorbed molecules. These particular nutraceuticals may assist with reducing the risks of certain diseases before pharmaceutical intervention is required, but without appropriate oral formulation they will have limited efficacy.

Innovative strategies are being attempted by the pharmaceutical industry for oral delivery of peptides including insulin, octreotide, salmon calcitonin (sCT) and parathyroid hormone (PTH). Approaches include entrapment in protective delivery vehicles, strategies for enhanced mucus penetration and epithelial permeation, as well as incorporation of excipients as protease enzyme inhibitors (Maher, Duffy, Ryan, \& Brayden, 2014). Chemical modification by a prodrug approach has been successful in improving small molecule oral bioavailability. For example, the anti-viral prodrug, valacyclovir is converted to acyclovir in 
vivo and improves oral bioavailability (Huttunen, Raunio, \& Rautio, 2011). Pro-vitamins are similar to synthetically- designed prodrugs and can yield improved oral bioavailability of supplements: pantothenic acid (vitamin $\mathrm{B}_{5}$ ) is unstable, so a stable alcohol, panthenol (provitamin $\mathrm{B}_{5}$ ), is the parent molecule that is subsequently oxidised to the bioactive form in vivo.

Here, we discuss factors which affect the oral delivery of different classes of isolated bioactive components (nutraceuticals) including fatty acids, bioactive peptides, micronutrients and phytochemicals, and we highlight strategies to improve their oral bioavailability (Fig. 1). Another class of nutraceuticals, bioactive carbohydrates have shown beneficial effects in vitro and in vivo, which are discussed in detail elsewhere (Brown, et al., 2014; Liu, Willför, \& Xu, 2015). Discussion of factors impacting the delivery of bioactive components within functional food and whole food matrices has been discussed extensively in previous reviews with highly on bioaccessibility, absorption and transformation (McClements, 2013b; McClements, et al., 2009; McClements, Li, \& Xiao, 2015; McClements \& Xiao, 2014). We review the potential of approaches used in pharmaceutical oral delivery (use of mucolytic agents and intestinal permeation enhancers), as well as new strategies based on nanotechnology and assess whether these might be applied to foodderived bioactive compounds in order to overcome the hurdles in orally delivering nutraceuticals.

\section{Factors affecting oral delivery of nutraceuticals}

Physicochemical and physiological factors affect oral delivery of nutraceuticals. However, solubility, stability and intestinal permeability are the major factors which impede effective delivery of compounds including fatty acids (e.g. omega-3 fatty acids), bioactive peptides (e.g. Ile-Pro-Pro), micronutrients (e.g. $\alpha$-tocopherol) and phytochemicals (e.g. resveratrol) (Fig. 1). Delivery systems should be designed based on overcoming specific factors which can affect the particular loaded nutraceutical.

\section{Nutraceutical compounds:}

\section{Fatty acids}

Long chain polyunsaturated fatty acids (LC-PUFA) are recognised for their role in brain development and potential to decrease risk of cardiovascular disease. Two fatty acids are essential for human health, $\alpha$-linolenic acid (ALA, an omega-3 fatty acid) and linoleic acid (LA, an omega-6 fatty acid). However, the process involved in converting ALA to 
eicosapentaenoic acid (EPA) and docosahexaenoic acid (DHA) in the body is inefficient and supplementation is often required (Deckelbaum \& Torrejon, 2012). Although cod liver oil has been an established source of EPA and DHA, there is interest in sustainable alternatives including krill oil, flax-seed and walnut oil (Adarme-Vega, Thomas-Hall, \& Schenk, 2014). EPA and DHA enhance production of anti-inflammatory lipid mediators, decrease production of pro-inflammatory cytokines and decrease serum C-reactive protein, a clinical marker of inflammation (Skulas-Ray, 2015). Supplementation with omega-3 fatty acids has antihyperlipidemic activity, reducing LDL-cholesterol and triglycerides (Maki, Yurko-Mauro, Dicklin, Schild, \& Geohas, 2014). Futhermore, Amarin Corporation's (Dublin, Ireland) Vascepa ${ }^{\circledR}$ icosapent ethyl (eicosapentaenoic acid ethyl ester) is an FDA-approved prescription medication for hypertriglyceridemia and there are plans to achieve a wider label for use in patients with moderately elevated triglyceride levels (Braeckman, Stirtan, \& Soni, 2015).

Delivery of omega-3 fatty acids is difficult due to low aqueous solubility in the small intestine and oxidative instability. Unsaturated fatty acids are prone to lipid oxidation, which is accelerated by exposure to air, light and heat, resulting in a loss in functionality and leading to off-flavour (Arab-Tehrany, et al., 2012). Upon reaching the small intestine, the fatty acids need to be liberated from the delivery matrix, often an oil capsule, to allow incorporation into mixed micelles, which seem to permeate the mucus layer and intestinal epithelia (Walker, Decker, \& McClements, 2015). Delivery platforms are required to reduce lipid oxidation, improve solubility and overcome poor mucus penetration.

\section{Bioactive peptides}

Proteins from food undergo enzymatic hydrolysis by digestive enzymes thereby releasing smaller peptides, which have bioactive properties if they can be absorbed. Some peptides inhibit angiotensin-converting enzyme (ACE), which can help maintain normal blood pressure and prevent escalation of hypertension by subverting the renin-angiotensinaldosterone system (Turpeinen, Jarvenpaa, Kautiainen, Korpela, \& Vapaatalo, 2013). Two such tripeptides have been focussed on: Ile-Pro-Pro (IPP) and Val-Pro-Pro (VPP), both isolated from milk $\beta$-casein (Fig. 1) following fermentation by Lactobacillus helveticus (Nakamura, et al., 1995). Other derived antihypertensive peptides include Val-Tyr-Pro (VYP, rice protein) (Chen, et al., 2013), Gly-Leu-Pro (GLP, chum salmon skin) (Lee, Jeon, \& Byun, 2014) and His-Leu-Phe-Gly-Pro-Pro-Gly-Lys-Lys-Asp-Pro-Val (HLFGPPGKKDPV, 
fertilised hen egg) (Duan, et al., 2014). These peptides can reduce systolic blood pressure following oral gavage to the spontaneously hypertensive rat (SHR). VPY is present in soy protein hydrolysate, inhibits pro-inflammatory cytokine production and reduces histological scoring of lesions in a rodent colitis model (Kovacs-Nolan, et al., 2012). Food-derived proteins such as $\alpha$-lactalbumin may also have anti-inflammatory action, and this is also of interest for potential treatment of inflammatory bowel disease (IBD) (Chatterton, Nguyen, Bering, \& Sangild, 2013).

Peptides are prone to pancreatic serine protease digestion by chymotrypsin, trypsin and elastase into small fragments and then further digestion to single amino acids by intracellular carboxypeptidases. Presence of Pro residues confers resistance to such enzymes (Gleeson, Heade, Ryan, \& Brayden, 2015). Due to their hydrophilic nature and high molecular weight however, peptides more than three residues long typically have low mucus penetration and intestinal permeability, resulting in variable oral bioavailability (Renukuntla, Vadlapudi, Patel, Boddu, \& Mitra, 2013). Delivery strategies therefore need to protect bioactive peptides from enzyme degradation and to enhance both mucus and intestinal permeability.

\section{Micronutrients}

Essential vitamins and minerals are required in small doses, with deficiencies leading to rickets (vitamin D), scurvy (vitamin C), neural tube defects (vitamin $B_{9}$ ), hypothyroidism (iodine), hypokalaemia (potassium), and Keshan's disease (selenium). A nutritionallybalanced diet will provide the required micronutrients to a healthy individual, however, there are many conditions that can still benefit from micronutrient supplementation including calcium for osteoporosis and iron for iron-deficient anaemia (Wallace, et al., 2015). The physiological role of micronutrients includes roles as co-enzymes for metabolic processes, antioxidants to remove reactive oxygen species (ROS), modulation of gene transcription and structural components.

Delivery of micronutrients are also limited by individual physicochemical characteristics, as they may be susceptible to bioaccessibility, stability, solubility, and bioavailability issues. Vitamins $\mathrm{C}$ and $\mathrm{E}$ are prone to oxidation during processing and delivery, while fat soluble vitamins (A, D, E and K) may not be liberated from the delivery matrix due to excessive lipophilicity. Micronutrient bioavailability is effected by multiple processes, for example, vitamin $\mathrm{E}$ is easily oxidised and has poor solubility. Anti-nutrients are compounds that 
interfere with the absorption of nutrients and limit their bioavailability. Calcium, iron and zinc can be chelated and cleared by dietary anti-nutrient phytate, hence the benefit of adding phytase to a micronutrient delivery system. Orally-delivered phytase can therefore improve oral calcium absorption in a pig model (Vigors, Sweeney, O'Shea, Browne, \& O'Doherty, 2014). Other dietary components act similarly by reducing mineral bioavailability, oxalic acid (spinach) binds calcium while glucosinolates (cruciferous vegetables) bind iodine. Therefore, oral delivery of minerals, somewhat ironically, may benefit from being taken in the absence of food.

\section{Phytochemicals}

"Phytochemicals" are a large group of plant-derived compounds (Fig. 1), which have been studied for their potent antioxidant activity and potential anti-inflammatory and antihyperlipidemic activity. They include phytosterols (e.g. plant stanol esters); organosulfers (e.g. allicin from garlic); terpenoids (e.g. lycopene carotenoid from tomatoes) and sesquiterpenes. Polyphenols are the largest class containing stilbenes (e.g. resveratrol from grapes), isoflavones (e.g. genistein from soybean) and flavonoids-based agents (e.g. kaempferol and naringenin from spinach and grapefruit respectively) (Gonzalez-Castejon \& Rodriguez-Casado, 2011). The anti-inflammatory mechanism of action of polyphenols involves modulation of nuclear factor kappa-light-chain-enhancer of activated B cells (NF$\kappa \mathrm{B}$ ), inhibition of Mitogen-activated protein kinases (MAPK) cascade, activation of nuclear factor erythroid 2-related factor 2 (Nrf2), and reduction in pro-inflammatory cytokines, all of which are relevant in treatment of IBD (Martin \& Bolling, 2015). Resveratrol improved expression of the cytoprotective $\mathrm{NAD}(\mathrm{P}) \mathrm{H}$ dehydrogenase, quinone 1 (NQO1), in cancer patients dosed with $\left[{ }^{14} \mathrm{C}\right]$-resveratrol (Cai, et al., 2015).

There are a multitude of factors affecting oral bioavailability of phytochemicals due to their unique physicochemical properties. For example, kaempferol has poor water solubility and favours alkaline $\mathrm{pH}$ conditions, resulting in low oral bioavailability $(2 \%)$ in a rat model (Barve, et al., 2009). It is also prone to biotransformation by Phase I oxidative metabolism and Phase II glucuronidation in intestinal epithelia (Barve, et al., 2009). Resveratrol is readily soluble in ethanol, however, it has poor water solubility and is easily photo-isomerised and metabolised by glucuronidation (Patel, et al., 2011). Oral delivery approaches for phytochemicals need to overcome solubility issues, provide a dose sufficient to overcome partial metabolism, and boost epithelial permeability. It is important to note however, that 
assumptions of straight-forward pharmacological dose-response concepts being applied to phytochemicals has been challenged by Cai et al., who demonstrated a non-linear dose response for the chemoprotective effects of resveratrol in humans and mice (Cai, et al., 2015), with efficacy seen at the low doses found in food, but not at high doses.

\section{Bioaccessibility and solubility in GIT}

Solubility is one of the first hurdles which must be overcome in oral delivery of bioactive molecules. The Food and Drug Administration (FDA) adopted the Biopharmaceutics Classification System (BCS) in 1995. It aims to predict in vivo performance of small drug molecules from immediate release solid oral dosage form based on in vitro measurements of solubility and permeability (Larregieu \& Benet, 2014). Permeability is typically determined across Caco-2 human in vitro intestinal epithelial monolayers grown on filters and solubility is determined in $250 \mathrm{ml}$ of aqueous media of simulated gastric fluid and simulated intestinal fluid over $\mathrm{pH}$ ranges 1.0-6.8 over the course of 24 hours. The BCS is also used as a guide for oral drug delivery formulation strategy, for example BCS Class III drugs are often formulated to improve intestinal permeability, while Class II drugs are formulated to improve solubility and cater for food effects (Buckley, Frank, Fricker, \& Brandl, 2013). Recently, McClements et al developed the Nutraceutical Bioavailability Classification System (NuBACS) (Fig. 2), factoring in major issues affecting the oral bioavailability of nutraceuticals (McClements, et al., 2015).

NuBACS introduces the concept of "bioaccessibility", the ability of the bioactive compound to be accessible to the body for absorption from the delivery matrix. Bioaccessiblity, absorption and transformation of nutraceuticals are features of the NuBACS, and this is relevant for functional foods. In contrast, oral delivery of pharmaceutical agents is achieved by capsules, tablets or suspensions and is governed by the BCS specifically in terms of solubility and permeability. Although some nutraceuticals may require liberation from a functional food or whole food, the focus here is on delivery strategies for isolated nutraceutical bioactives, therefore, liberation refers to release from a delivery vehicle or formulation prior to solubilisation. Solubility is however, a major hurdle for certain nutraceuticals, particularly fatty acids and phytochemicals. 


\section{Degradation and Metabolism}

Degradation and metabolism are hurdles which an oral delivery system needs to overcome after solubilisation has been achieved. The recently developed biopharmaceutics drug disposition classification system (BDDCS) factors in drug metabolism by Phase I and II processes and is useful in predicting drug-drug interactions that may occur in the intestine and liver (Larregieu \& Benet, 2014). Enzymatic metabolism is particularly relevant to fatty acids and peptides which are targeted by lipases and peptidases respectively. Lingual and gastric lipases account for a small amount of lipid hydrolysis, whereas pancreatic lipases act on bile-derived emulsified lipids resulting in 90\% lipid digestion (Aarak, et al., 2013). However, EPA and DHA are resistant to pancreatic lipase hydrolysis due to the location of bond conjugation in the carbon chain (Akanbi, Sinclair, \& Barrow, 2014). Bioactive peptides are prone to peptidases which access specific labile amino acids, although certain peptides are stable due to a lack of target amino acids for peptidases.

On the other hand, metabolism can assist in absorption of some phytochemicals: the flavonoid quercetin, is commonly found as a glycoside of either glucose or rutinose, but the capacity to metabolise the sugar moiety effects quercetin's bioavailability. Quercetin-4'-Oglucoside is absorbed intact in the small intestinal lumen by sodium-glucose transporter 1 (SGLT1) and then hydrolysed by intracellular $\beta$-glucosidases, thereby cleaving the sugar moiety, which then passively diffuses across the basolateral membrane (Lotito, Zhang, Yang, Crozier, \& Frei, 2011). On the other hand quercetin-3'- $O$-rutinoside does not permeate the small intestine, instead caecally-located bacterial $\alpha$-rhamnosidases convert it to the quercetin, aglycone, which in turn is absorbed from the colon.

\section{Intestinal permeation}

Nutraceuticals may have limited capacity to permeate the gut wall. Prior to reaching the epithelia, bioactives must traverse intestinal mucus. Mucus is a complex hydrogel consisting of a mixture of glycoproteins, lipids, and sloughed epithelial cells. Interaction with mucus reduces permeability of mucoadhesive lipophilic molecules or large molecules due to steric blocking (Sigurdsson, Kirch, \& Lehr, 2013). Lipophilic bioactives can be transported through the mucus layer by mixed micelles formed from bile salts, phospholipids and free fatty acids. Therefore, the lipophilic molecules, EPA, DHA, resveratrol, and kaempferol may pass through mucus in association with luminal-derived moieties. Nanoparticles coated with small 
hydrophilic polymers including low molecular weight high density polyethylene glycol (PEG) and polysialic acid, can slip through the mesh of mucus potentially allowing for release of nutraceutical at intestinal epithelia or uptake of nutraceutical-entrapped nanoparticles (Ensign, et al., 2013).

Upon diffusion through the mucus, there are several routes which a bioactive agent may permeate the intestinal epithelia. Transport via the paracellular route requires movement through tight junctions. A molecular radius between 10-50 A and molecular weight <500 Da is required and the bioactive must be hydrophilic in nature (Larregieu \& Benet, 2014). Paracellular transport reduces risk of intracellular metabolism, which is relevant for phytochemicals and bioactive peptides. Transcellular transport involves molecules passing across the apical membrane by passive diffusion, receptor mediation or endocytosis. Hydrophobic molecules can pass across the phospholipid bilayer by passive diffusion. According to Fick's law of diffusion molecules with a relatively high oil-water partition coefficient $\left(\mathrm{K}_{\mathrm{ow}}\right)$ or greater hydrophobicity $(\log P)$ can pass the cell membrane more efficiently (e.g. $\beta$-carotene, $\log P=15.2$ ) compared to molecules with lower values (e.g. IPP, $\log P=1.07$; vitamin $\mathrm{C}, \log P=2.77$ ) (McClements, et al., 2015). There is a balance required, as the greater the $\log P$ the less the solubility: a $\log P$ of $<2.5$ may be optimal, however, this depends on the formulation or presence of bile salts and surfactants, which may assist in solubilising lipophilic nutraceuticals and presenting them as components of mixed micelles.

The epithelium of the small and large intestine has a multitude of transporters localised on the apical membrane which have roles in uptake of nutrients and absorption of drugs. These membrane bound proteins are relevant to the uptake of many nutraceuticals. Fatty acids are transported by intestinal fatty acid-binding proteins (I-FABP), and bioactive di- and tripeptides are carried by the proton coupled peptide transporter (PEPT1). Calcium uptake is mediated by the vitamin D receptor, while vitamin $\mathrm{C}$ is carried on the sodium-vitamin $\mathrm{C}$ cotransporter (SVCT) (Lin, Yee, Kim, \& Giacomini, 2015). In the case of IPP at least two uptake pathways are likely to play a role: the paracellular route due to its low molecular weight (MW) and the transcellular route due to its interaction with the PEPT1 carrier. Appropriate exploitation of one or both of these intestinal permeation routes may enhance absorption of these types of molecules. 


\section{Food-based strategies for improving oral delivery of nutraceuticals Delivery vehicles}

A delivery vehicle can control delivery and release of the nutraceutical. The use of delivery vehicles in the pharmaceutical industry has been investigated for oral delivery of antibiotics, vaccines, cancer therapeutics and biopharmaceuticals (Choonara, et al., 2014; Ryan, et al., 2013). Due to the hurdles which must be overcome to orally deliver a therapeutically effect dose of a nutraceutical, delivery vehicles are of increasing interest. In particular the utilisation of food grade ingredients with GRAS (generally regarded as safe) status to create the delivery vehicle is a promising area of current research. Furthermore, nutraceutical loaded in pharmaceutical grade delivery vehicle formulations has also emerged in recent years.

\section{Lipid and surfactant based systems}

Liposomes or nanoliposomes are formed when phospholipids self-assemble into a lipid bilayer due to hydrophobic interactions with the fatty acid chain. Niosomes are formed when non-ionic surfactants assemble into similar structures (Fig. 3). Cholesterol is often added to the formulation as it increases rigidity strength of the membrane and confers steric stability. Egg yolk- and soy-derived phosphatidylcholines are commonly used to form liposomes, whereas Tween ${ }^{\circledR} 80$, Span ${ }^{\circledR} 80$ and sucrose laurate have been used to form niosomes (Nui, et al., 2012; Pando, Gutiérrez, Coca, \& Pazos, 2013; Shin, Chung, Kim, Joung, \& Park, 2013). There are some characteristic differences between liposomes and niosomes, particularly the oxidative stability of the particles dye to phospholipid oxidative degradation. They are both suitable for loading of lipophilic nutraceuticals in the inner core of the bilayer membrane, as well as hydrophilic compounds in the aqueous core.

The carotenoid class of phytochemicals show strong anti-oxidative potential, however, they are highly hydrophobic $(\log P>13)$, which makes them suitable candidates for liposome formulation. Lutein was found to be most easily incorporated from a series of carotenoids with the rank order lutein $>\beta$-carotene $>$ lycopene $>$ canthaxanthin (Xia, et al., 2015). In vitro release showed lycopene and canthaxanthin exhibited a burst release from liposomes whereas lutein and $\beta$-carotene displayed a sustained release (Tan, et al., 2014). Curcumin is another lipophilic phytochemical with anticancer and antimalarial activity, which can be incorporated into liposomes (Shin, et al., 2013). Curcumin was soluble upon in vitro lipolysis, and permeation across Caco-2 monolayers was enhanced compared to free curcumin (Memvanga, 
Coco, \& Préat, 2013). When delivered in combination with $\beta$-arteether (an antimalarial drug), curcumin loaded liposomes increased survival rate in rodents compared to $\beta$-arteether or curcumin alone, thereby showing potential of the liposome formulation.

Due to their structure, liposomes and niosomes have the potential for co-encapsulation. One example is to have curcumin-loaded cyclodextrin in the core along with a curcumin-loaded bilayer membrane, a formulation which induced apoptosis in the osteosarcoma xenograft mouse model (Dhule, et al., 2012). Niosomes have co-encapsulated antioxidant nutraceuticals, two examples of which are gallic acid (hydrophilic core) with curcumin, and ascorbic acid (hydrophilic core) with quercetin. Co-encapsulation of two antioxidants resulted in an improved antioxidant scavenging effect in vitro compared to individual molecules (Tavano, Muzzalupa, Picci, \& de Cindo, 2014).

Nanoemulsions are colloidal dispersions formed from emulsified oils in water $(\mathrm{O} / \mathrm{W})$ with a core-shell structure (Fig. 3). Emulsions are commonly found in food and examples are mayonnaise $(\mathrm{O} / \mathrm{W})$ emulsion stabilised by egg yolk lecithin, or butter $(\mathrm{W} / \mathrm{O})$ emulsion stabilised by milk proteins. Nanoemulsions differ from traditional emulsions in a number of ways: $<100 \mathrm{~nm}$ in droplet size, high optical clarity and increased stability against flocculation and coalescence. Nanoemulsions can be fabricated by low-energy (spontaneous formation due to high concentrations of surfactants) or high-energy (mechanical disruption of oil phase resulting in nano-sized droplets). They are suitable for loading of lipophilic nutraceuticals, which are solubilised in the oil phase prior to addition of surfactant and/or mechanical disruption, resulting in an entrapped bioactive (McClements, 2013a).

The loading of phytochemicals into nanoemulsions such as curcumin, genistein, and the citrus flavonoid, 5-demethyltangeretin (5DT), greatly improved solubility in simulated intestinal fluid from $\sim 10 \%$ to $80 \%$ (Aditya, et al., 2013). Formation of emulsions from essential oils is of particular interest, as it only requires addition of an emulsifier to a bioactive oil. Many of these oils exhibit antimicrobial and antioxidant activity and have been investigated to prevent food spoilage (Xue \& Zhong, 2014). Lipid oxidation may be a limitation of nanoemulsions, although addition of an antioxidant like ascorbic acid was found to reduce lipid hydroperoxide production of soybean oil emulsions (Uluata, McClements, \& Decker, 2015). The size of the lipid droplet effects epithelial cellular uptake of flavonoid loaded nanoemulsions in HCT116 cells, with $67 \mathrm{~nm}$ and $125 \mathrm{~nm}$ showing 4-fold higher uptake compared to $203 \mathrm{~nm}$ (Zheng, et al., 2014). Coenzyme $\mathrm{Q}_{10}\left(\mathrm{CoQ}_{10}\right)$ is a powerful 
antioxidant which is highly hydrophobic and is also required for healthy mitochondrial function. $\mathrm{CoQ}_{10}$ formulated into a salmon oil-salmon lecithin nanoemulsion had a 10-fold increase in plasma concentration compared to water vehicle after oral gavage in Wistar rat (Fig. 4) (Belhaj, et al., 2012). Tangeretin, a citrus flavone, has shown potential as an anticancer agent when formulated into a nanoemulsion it improved in vitro tumour suppression and reduced incidence of colonic adenomas compared to control in the azoxymethan/dextran sodium sulphate (AOM/DSS)-induced colitis mouse model (Ting, Chiou, Pan, Ho, \& Huang, 2015).

Solid lipid nanoparticles (SLNs) are O/W emulsions in which the internal lipid core has been fully or semi-solidified (Fig. 3). SLNs are prepared as a 'hot' nanoemulsions at a temperature above the melting point of the particular lipid, and temperature is rapidly decreased inducing lipid crystallisation. SLNs have shown promise as a pharmaceutical oral delivery system since the early 90's as they combine the advantages of polymeric particles, liposomes, and emulsions. $\beta$-carotene is prone to oxidation and degradation over time and during GIT transit. When formulated into a SLN (stearic acid emulsified with lecithin), degradation was prevented for up to 20 days incubation at room temperature (Helgason, et al., 2009). Curcumin formulated into a SLN showed improved permeability across co-cultured monolayers of HT29-MTX and Caco-2 cells compared to curcumin formulated in a nanoemulsion in vitro, although only $1 \%$ of loaded curcumin permeated (Guri, Gulseren, \& Corredig, 2013). The serum area under the curve (AUC) concentration of a $50 \mathrm{mg} / \mathrm{kg}$ of either free curcumin or curcumin-loaded SLNs in a rat model showed that the latter increased the AUC to $41 \mu \mathrm{g} / \mathrm{mL}$ compared to $1 \mu \mathrm{g} / \mathrm{mL}$ (Kakkar, Singh, Singla, \& Kaur, 2011). Resveratrol is sensitive to light, however, resveratrol-loaded SLNs improved the photostability of the bioactive and improved its oral bioavailability 8-fold compared to resveratrol solution in a rat model (Pandita, Kumar, Poonia, \& Lather, 2014). SLN also improved oral bioavailability with other bioactives in rat studies: candesartan cilexetil (a treatment for hypertension) and $\beta$ arteether (second line treatment for malaria) (Dwivedi, et al., 2014; Zhang, Gao, Bu, Xiao, \& $\mathrm{Li}, 2012)$.

\section{Biopolymer based systems}

Polyelectrolyte complexes (PECs) are formed by electrostatic interaction between oppositely charged biopolymers e.g. iota carrageenan and protamine (Fig. 3). Entrapped PECs are formed by solubilising nutraceuticals in either the positively or negatively charged 
biopolymer, and then the opposite charged biopolymer is mixed in. PECs formed between cationic gelatin and gum Arabic swelled and aggregated at $\mathrm{pH} 4.5$, whereas they were stable between pH 5.5 - 7.5 and had diameters of 110 - $160 \mathrm{~nm}$ (Sarika, Pavithran, \& James, 2015). These PECs may be promising carriers for nutraceuticals, however the swelling at lower $\mathrm{pH}$ poses issues at gastric $\mathrm{pH}$ values.

GRAS food biopolymers are an abundant source for polyelectrolyte complexation e.g. amylose, starch, pectin, carrageenan and chitosan. Resveratrol complexed in a gelatin PEC showed improved anti-proliferative efficacy than free resveratrol and improved bioavailability in mice compared to free resveratrol solution after intravenous injection (Karthikeyan, Rajendra Prasad, Ganamani, \& Balamurugan, 2013). PECs are a class of nanoparticles which are not well exploited for nutraceuticals to date with limited in vivo data; on the other hand they have shown promise for therapeutic peptides. For example, insulin and sCT display improved stability when complexed in PECs (Lu, et al., 2012; Ryan, et al., 2013).

Hydrogels are a 3D polymer network with an extremely high abundance of water, which when appropriately cross-linked can form hydrogel particles in the nano-sized range (Fig. 3). These can be formed from protein gelation via physical, chemical or biochemical methods which self-crosslink between denatured proteins, whereas, carbohydrate based hydrogels generally require addition of an ionic cross-linker. They may be composed of GRAS biopolymers including pectin, alginate, carrageenans, agar, chitosan, gelatin, whey protein, caseins, soy protein. Hydrogel particles can also contain dispersed oil droplets for carrying lipophilic molecules. When $\beta$-carotene was formulated into each of a conventional emulsion, a hydrogel, and an oil dispersion-"filled" hydrogel, the latter had an improved release of the bioactive compared to both formulations due to solubilising effect and increased lipid surface area (Mun, Kim, \& McClements, 2015).

Comprehensive preclinical in vivo studies of oral delivery of hydrogel particles with nutraceutical bioactives are lacking similar to PECs, providing an area of under-exploited delivery vehicles. However, one rodent study suggested that Nile Red-loaded conventional emulsions had superior oral bioavailability compared to lipid-entrapped hydrogels ( $\mathrm{Li}, \mathrm{Kim}$, Park, \& McClements, 2012). Caveats were that the diameters of particles were not comparable ( $0.36 \mu \mathrm{m}$ vs. $510 \mu \mathrm{m}$ respectively) and the loading of a nutraceutical may yield different results compared to Nile Red. Insulin has been delivered orally in vivo in hydrogels 
in rodents, but there are major issue in how to translate such formulations from rodent models to clinical trials (Déat-Lainé, et al., 2013). Hydrogel particles formulated from whey protein and alginate were loaded with insulin and yielded $2.4 \%$ relative bioavailability after intraduodenal instillation in a rat model. Polyacrylic acid-derived hydrogels were cross-linked with poly(L-glutamic acid) and then loaded with insulin (60 IU $/ \mathrm{kg})$; this formulation resulted in a 33\% reduction of plasma glucose levels in the streptozotocin (STZ)-induced rat Type 1 diabetes model (Gao, He, Xiao, Zhuang, \& Chen, 2013). Finally, insulin was also loaded into lectin-functionalized and ionically-gelated carboxymethylated kappa-carrageenan particulates and induced $14 \%$ relative bioavailability by the oral route compared to subcutaneous injection in rats (Leong, et al., 2011).

Protein-carbohydrates (self-assembly structures) are formed from interaction between anionic polysaccharides and cationic protein surface groups, similar to PECs. Alternatively, they may be formed by thermal denaturation or aggregation of a globular protein followed by addition of an ionic polysaccharide, while still relying in part on electrostatic charge (Fig. 3). Vitamin $\mathrm{D}_{2}$ was bound to $\beta$-lactoglobulin and complexed with anionic pectin, resulting in stable nanoparticles 50-70 nm, which improved the shelf-life stability of the bioactive compared to storage in water and uncomplexed $\beta$-lactoglobulin (Ron, Zimet, Bargarum, \& Livney, 2010). Nanoencapsulation of anthocyanins in a complexation of whey protein and pectin also resulted in improved protection against thermal degradation (Arroyo-Maya \& McClements, 2015). Due to the amphiphilic nature of proteins, it is possible to load hydrophilic or lipophilic nutraceuticals inside the self-assembly structured particulates.

Curcumin was complexed into chitosan-zein particulates, improved thermal and UV stability and anti-oxidative scavenging capacity was retained (Liang, et al., 2015). Similarly, when curcumin was complexed in a carboxymethyl chitosan- kafirin (a prolamin protein from sorghum) particulates, it again improved UV stability and improved cellular uptake in Caco-2 (Xiao, Nian, \& Huang, 2015). EGCG is an abundant polyphenol from green tea and a potent antioxidant; it had a burst release profile and retained cytotoxicity against cancer cell lines in vitro when complexed in a chitosan-caseinophosphopeptide particulate (Hu, Xie, Zhang, \& Zeng, 2014). Furthermore, EGCG complexed in ovalbumin-dextran, saw a small increase in permeability across Caco-2 monolayers compared to free EGCG (Li \& Gu, 2014). Resveratrol complexed in a zein-based nanoparticle improved oral bioavailability 19-fold 
compared to resveratrol solution (Fig. 5) and reduced serum TNF- $\alpha(15 \%)$ against control in a mouse model of endotoxic shock (Penalva, et al., 2015).

\section{Intestinal Absorption Improvements}

Although delivery vehicles increase permeability in vitro and in vivo animal models, there is still potential to further increase the intestinal permeability. Intestinal permeation enhancers (PEs) have been researched for oral delivery of hydrophilic peptide drugs in the last two decades (Choonara, et al., 2014). Improving nutraceutical absorption can be achieved in two ways (Fig. 6); improve mucodiffusion of lipophilic agents (e.g. omega-3 fatty acids and phytochemicals) using mucolytics; improve paracellular and transcellular permeability of bioactive peptides, micronutrients and hydrophilic phytochemicals using PEs.

\section{Mucolytics}

Mucus diffusion enhancers such as $\mathrm{N}$-acetylcysteine (NAC), bromelain, and papain hold potential for nutraceuticals affected by inability to penetrate the small intestinal mucus layer. Papain is a mucolytic protease found in papaya; when decorated on nanoparticles, it improved permeation and reduced mucus viscosity in vitro (Müller, et al., 2012). Bromelain, a pineapple stem mucolytic enzyme, was formulated on the surface of nanoparticles and compared against papain for in vitro mucus permeation resulting in enhanced penetration: bromelain > papain > conventional nanoparticles (Pereira de Sousa, et al., 2015). Papain decorated nanoparticles were also shown to penetrate into deeper mucus layers, when delivered by oral gavage in a rat model, with higher retention within the jejunum (Müller, Perera, König, \& Bernkop-Schnürch, 2014). This is of particular interest, as the jejunum is the main target for nutraceutical bioactive absorption.

NAC is an antioxidant nutritional supplement and it is also used as a mucolytic agent by breaking disulphide bonds (Yuan, et al., 2015). When an intestinal PE, tetradecyl maltoside (TDM) was tested on Caco-2- and mucus-producing HT29-MTX-E12 monolayers, it was shown that NAC-pre-treatment on E12 monolayers resulted in comparable apparent permeability $\left(\mathrm{P}_{\mathrm{app}}\right)$ values of salmon calcitonin across Caco-2 and E12 (Petersen, Nielsen, Rahbek, Guldbrandt, \& Brayden, 2013). The blood serum levels of fluorescein isothiocyanate-dextran MW 4000 (FD-4, a fluorescent marker molecule for the paracellular route) was improved 2.8-fold upon intra-jejunal administration of NAC (5\% w/v) in rats, and 
showed a mucolytic effect up to 60 minutes (Takatsuka, Kitazawa, Morita, Horikiri, \& Yoshino, 2006).

The application of mucolytic agents also holds promise for lipophilic nutraceuticals, which interact with glycoproteins and lipids in mucus (Sigurdsson, et al., 2013). This interaction reduces the likelihood of epithelial permeation as mucus is continuously turned over and would result in the bioactive being washed away. Whereas mucolytics reduce this risk of this occurring by enhancing mucus penetration. Mucolytics are most often investigated in the context of airway mucus in cystic fibrosis, where NAC is used at high concentrations. Recently a synthetic thiol-carbohydrate (methyl 6-thio-6deoxy- $\alpha$-D-galactopyranoside) was found to be a more potent mucolytic (Yuan, et al., 2015). Co-administration of lipophilic nutraceuticals and mucolytics in the context of an enteric coated oral dosage form may therefore control release in the small intestine, improve mucus penetration and improve absorption.

\section{Intestinal Permeation Enhancers (PEs)}

PEs can increase oral bioavailability assuming that the nutraceutical can also survive liver first pass metabolism. Of these, the medium chain fatty acid (MCFS) sodium caprate $\left(\mathrm{C}_{10}\right)$ is well established as a food additive and was a component of an antibiotic suppository once marketed in Sweden and Japan (Maher, et al., 2014). Ideally, PEs should be pharmacologically inert, have excipient or Generally-Regarded-As-Safe (GRAS) status, and have a history of use in man. PEs are often used for peptide oral delivery with candidates including sCT, insulin, glucagon-like Peptide 1 (GLP-1) analogues, and octreotide. For example, The technology of Enteris Biopharma (New Jersey, USA) is currently in Phase II with a PE (an acyl carnitine), a peptidase inhibitor (citric acid) and parathyroid hormone (Stern, Mehta, \& Carl, 2013). The technology of Chiasma (Jerusalem, Israel) recently completed Phase III for oral octreotide and it comprises a PE (caprylic acid) in a water-in-oil suspension (Tuvia, et al., 2012). Merrion Pharmaceuticals (Dublin, Ireland) uses a gastrointestinal permeation enhancement technology (GIPET $\left.{ }^{\mathrm{TM}}\right)$ built around the PE $\left(\mathrm{C}_{10}\right)$ in matrix tablets and it completed an oral Phase I study with GLP-1 (Karsdal, et al., 2015). Finally, the technology of Oramed (Jerusalem, Israel) is has reached Phase IIb for oral insulin and it comprises a PE (EDTA) and soy-bean trypsin inhibitor (Lewis \& Richard, 2015). 
MCFA-based PEs act by re-organising proteins at the epithelial tight junction (Fig. 6), (e.g. tricellulin and claudin 5), and by mild detergent fluidizing effect on the plasma membrane (Brayden, Gleeson, \& Walsh, 2014; Krug, et al., 2013). This allows for poorly permeable molecules to either transiently permeate across tight junctions, or possibly to be entrapped in mixed micelles with capacity to cross lipid bilayers. PEs generally cause a reduction of transepithelial electrical resistance (TEER) using in vitro and ex vivo intestinal epithelial models. This reduction suggests an opening of tight junctions or perturbation of the epithelia. They have shown significant increase in apparent permeability of $\left[{ }^{14} \mathrm{C}\right]$-mannitol (a marker for paracellular transport) and FD-4 across isolated intestinal mucosa on the Ussing chamber model. For example, $\mathrm{C}_{10}$ showed an increase in FD-4 permeability in Caco-2 monolayers, an 8-fold increase across isolated colonic mucosa and a 2-fold increase in colonic instillations in vivo (Brayden \& Walsh, 2014). This effect is also associated with a temporary perturbation of the intestinal epithelia. However this mild damage induced by MCFA such as $\mathrm{C}_{10}$ is quickly repaired, which was shown after in situ intestinal injections in rats (Wang, Maher, \& Brayden, 2010). The continuing progress of $\mathrm{C}_{10}$ and other PEs in clinical trials for oral peptides is also addressing safety aspects that may be associated with increased oral bioavailability.

Many of these PEs are commonly used in food processing with GRAS status or are of food origin. Candidates PEs include coco-glucosides (CG), chitosan derivatives, bromelain, EDTA, oleic acid, alkyl maltosides, medium chain fatty acids (MCFA) and sucrose esters (Aguirre, et al., 2014; Szüts \& Szabó-Révész, 2012). Furthermore, many isolated food components can modulate tight junction integrity in vitro by enhancing permeability by opening tight junctions. Although many of these PEs work especially well in the colon, the target site for absorption of nutraceuticals is predominantly the jejunum. The capacity for enhancement was tested in different regions of the rat intestine with $\mathrm{C}_{10}$ and insulin using an in situ loop model, which showed a rank order of plasma glucose reduction: colon > ileum > jejunum >duodenum (Morishita, Morishita, Takayama, Machida, \& Nagai, 1993). The apical membrane of the small intestine is often exposed to bile salts and fatty acids resulting in resistance to surfactant perturbation compared to colon. TEER decreased in isolated rat jejunum and ileum using TDM and CG, however, there was no increase in the permeability of FD-4. This lack of effect from these PEs may be due to the marker MW of 4kDa, because when HT-29/B6 monolayers were treated with $\mathrm{C}_{10}$, a 3-fold increase in fluorescein (330Da) was detected (Krug, et al., 2013). Isolated rat jejunum was treated with $\mathrm{C}_{10}$ and sodium salt of 
10-undecylenic acid ( $\mathrm{uC}_{11}$, an antifungal agent), a 1.4-3.6-fold increase was shown for FITClabelled IPP (714 Da) and LKP (745 Da) (Brayden \& Walsh, 2014; Gleeson, et al., 2015). Therefore, using the appropriate PE in the jejunum holds the potential to improve the permeability of nutraceuticals and potentially improve oral bioavailability. On the other hand, kaempferol, curcumin and daidzein may have potential for useful application in inflammatory bowel disease (Kosińska \& Andlauer, 2013), where they can repair membranes and reduce abnormally high epithelial permeability.

\section{Conclusions}

Nutraceuticals offer the opportunity to prevent onset and escalation of lifestyle-associated diseases due to their range anti-oxidative, anti-inflammatory, anti-hyperlipidemic and antihypertensive activities. Progress has been made in adopting Pharma oral delivery strategies to improve solubility, stability and permeability of nutraceutical bioactives. In particular, solubilisation technologies can overcome issues associated with the delivery of hydrophobic compounds (e.g. resveratrol and curcumin) using lipid-based systems. There has often been too much emphasis put on the in vitro assays suggesting anti-oxidative, antiinflammatory and anti-hypertensive actions of nutraceuticals. One of the main issues is that many nutraceuticals are not tested in in vivo preclinical studies, it is therefore impossible to assess whether they are predictive of efficacy. However, at least some nutraceuticals can be efficiently formulated and show promising data in rodent models (Dhule, et al., 2012; Kakkar, et al., 2011; Karthikeyan, et al., 2013; Memvanga, et al., 2013; Pandita, et al., 2014; Penalva, et al., 2015). In relation to clinical trials of nutraceuticals, these are costly and rare, difficult to design, and display conflicting results. For example, opposing effects have been detected in man for antihypertensive tripeptide, IPP, although a meta-analysis concluded that it has a hypotensive effect in pre-hypertensive subjects (Xu, Qin, Wang, Li, \& Chang, 2008). A renewed emphasis on clinical data is required to establish a relationship between nutraceuticals in delivery systems and possible health benefits. However, to obtain a health claim, regulations can vary between countries. The US Food and Drug Administration (FDA) has granted category ' $A$ ' status to soy with the health claim "reduction of the risk of heart disease". Yet in Europe, the European Food and Safety Authority (EFSA) rejected a similar application due to lack of confirmatory data on the reduction in blood LDL-cholesterol due to the intake of isolated soy protein (Girgih, Myrie, Aluko, \& Jones, 2013; Mannarino, Ministrini, \& Pirro, 2014). 
Absorption enhancement is an area yet to be used for improving oral nutraceutical delivery. Mucolytics and PEs hold potential to improve absorption of both lipophilic and hydrophilic nutraceuticals, particularly as many of these are food-grade and/or food additives. However, there is a question regarding the safety of PEs due to perturbation of the intestinal epithelia through mild detergent-based surfactant effects, even for agents with GRAS status or with a history of use in man (Chassaing, et al., 2015). Although toxicity of various PEs under acute dosing regimens has not been found in clinical trials for oral peptides to date (Melmed, et al., 2015; Tuvia, et al., 2014), PEs would not be suitable for administration to patients with inflammatory bowel- or coeliac disease (Laukoetter, Nava, \& Nusrat, 2008) and chronic dosing studies are yet to be investigated for most PE examples (McCartney, Gleeson, \& Brayden, 2016). There is therefore potential to harness strategies in oral drug delivery to nutraceutical delivery using established excipient and GRAS-listed reagents. This will result in an overall improved knowledge of delivery systems allowing for development of oral nutraceutical systems for important candidate molecules.

\section{Acknowledgements}

This study was supported by an Irish Department of Agriculture Food Institutional Research Measure (FIRM) grant 'NUTRADEL,' grant number 11F042.

\section{References}

Aarak, K. E., Kirkhus, B., Holm, H., Vogt, G., Jacobsen, M., \& Vegarud, G. E. (2013). Release of EPA and DHA from salmon oil - a comparison of in vitro digestion with human and porcine gastrointestinal enzymes. British Journal of Nutrition, 110, 14021410 .

Adarme-Vega, T. C., Thomas-Hall, S. R., \& Schenk, P. M. (2014). Towards sustainable sources for omega-3 fatty acids production. Current Opinion in Biotechnology, 26, 14-18.

Aditya, N. P., Shim, M., Lee, I., Lee, Y., Im, M. H., \& Ko, S. (2013). Curcumin and genistein coloaded nanostructured lipid carriers: in vitro digestion and antiprostate cancer activity. Journal of Agricultural and Food Chemistry, 61, 1878-1883.

Aguirre, T. A. S., Rosa, M., Guterres, S. S., Pohlmann, A. R., Coulter, I., \& Brayden, D. J. (2014). Investigation of coco-glucoside as a novel intestinal permeation enhancer in rat models. European journal of pharmaceutics and biopharmaceutics, 88, 856-865.

Akanbi, T. O., Sinclair, A. J., \& Barrow, C. J. (2014). Pancreatic lipase selectively hydrolyses DPA over EPA and DHA due to location of double bonds in the fatty acid rather than regioselectivity. Food Chemistry, 160, 61-66. 
Arab-Tehrany, E., Jacquot, M., Gaiani, C., Imran, M., Desobry, S., \& Linder, M. (2012). Beneficial effects and oxidative stability of omega-3 long-chain polyunsaturated acids. Trends in Food Science \& Technology, 25, 24-33.

Arroyo-Maya, I. J., \& McClements, D. J. (2015). Biopolymer nanoparticles as potential delivery systems for anthocyanins: Fabrication and properties. Food Research International, 69, 1-8.

Barve, A., Chen, C., Hebbar, V., Desiderio, J., Saw, C. L., \& Kong, A. N. (2009). Metabolism, oral bioavailability and pharmacokinetics of chemopreventive kaempferol in rats. Biopharmaceutics and Drug Disposition, 30, 356-365.

Belhaj, N., Dupuis, F., Arab-Tehrany, E., Denis, F. M., Paris, C., Lartaud, I., \& Linder, M. (2012). Formulation, characterization and pharmacokinetic studies of coenzyme Q10 PUFA's nanoemulsions. European Journal of Pharmaceutical Sciences, 47, 305-312.

Braeckman, R. A., Stirtan, W. G., \& Soni, P. N. (2015). Effects of Icosapent Ethyl (Eicosapentaenoic Acid Ethyl Ester) on Pharmacokinetic Parameters of Rosiglitazone in Healthy Subjects. Clinical Pharmacology in Drug Development, 4, 143-148.

Braithwaite, M. C., Tyagi, C., Tomar, L. K., Kumar, P., Choonara, Y. E., \& Pillay, V. (2014). Nutraceutical-based therapeutics and formulation strategies augmenting their efficiency to complement modern medicine: An overview. Journal of Functional Foods, 6, 82-99.

Brayden, D. J., Gleeson, J. P., \& Walsh, E. G. (2014). A head-to-head multi-parametric high content analysis of a series of medium chain fatty acid intestinal permeation enhancers in Caco-2 cells. European journal of pharmaceutics and biopharmaceutics, $88,830-839$.

Brayden, D. J., \& Walsh, E. (2014). Efficacious intestinal permeation enhancement induced by the sodium salt of 10-undecylenic acid, a medium chain fatty acid derivative. The AAPS journal, 16, 1064-1076.

Brown, E. S., Allsopp, P. J., Magee, P. J., Gill, C. I., Nitecki, S., Strain, C. R., \& McSorley, E. M. (2014). Seaweed and human health. Nutrition Reviews, 72, 205-216.

Buckley, S. T., Frank, K. J., Fricker, G., \& Brandl, M. (2013). Biopharmaceutical classification of poorly soluble drugs with respect to "enabling formulations". European Journal of Pharmaceutical Sciences, 50, 8-16.

Cai, H., Scott, E., Kholghi, A., Andreadi, C., Rufini, A., Karmokar, A., Britton, R. G., Horner-Glister, E., Greaves, P., Jawad, D., James, M., Howells, L., Ognibene, T., Malfatti, M., Goldring, C., Kitteringham, N., Walsh, J., Viskaduraki, M., West, K., Miller, A., Hemingway, D., Steward, W. P., Gescher, A. J., \& Brown, K. (2015). Cancer chemoprevention: Evidence of a nonlinear dose response for the protective effects of resveratrol in humans and mice. Science Translational Medicine, 7, 298 ra117.

Chassaing, B., Koren, O., Goodrich, J. K., Poole, A. C., Srinivasan, S., Ley, R. E., \& Gewirtz, A. T. (2015). Dietary emulsifiers impact the mouse gut microbiota promoting colitis and metabolic syndrome. Nature, 519, 92-96.

Chatterton, D. E., Nguyen, D. N., Bering, S. B., \& Sangild, P. T. (2013). Anti-inflammatory mechanisms of bioactive milk proteins in the intestine of newborns. The International Journal of Biochemistry and Cell Biology, 45, 1730-1747. 
Chen, J., Liu, S., Ye, R., Cai, G., Ji, B., \& Wu, Y. (2013). Angiotensin-I converting enzyme (ACE) inhibitory tripeptides from rice protein hydrolysate: Purification and characterization. Journal of Functional Foods, 5, 1684-1692.

Choonara, B. F., Choonara, Y. E., Kumar, P., Bijukumar, D., du Toit, L. C., \& Pillay, V. (2014). A review of advanced oral drug delivery technologies facilitating the protection and absorption of protein and peptide molecules. Biotechnology Advances, $32,1269-1282$.

Déat-Lainé, E., Hoffart, V., Garrait, G., Jarrige, J.-F., Cardot, J.-M., Subirade, M., \& Beyssac, E. (2013). Efficacy of Mucoadhesive Hydrogel Microparticles of Whey Protein and Alginate for Oral Insulin Delivery. Pharmaceutical Research, 30, 721734.

Deckelbaum, R. J., \& Torrejon, C. (2012). The Omega-3 Fatty Acid Nutritional Landscape: Health Benefits and Sources. J Nutr, 142, 587S-591S.

Dhule, S. S., Penfornis, P., Frazier, T., Walker, R., Feldman, J., Tan, G., He, J., Alb, A., John, V., \& Pochampally, R. (2012). Curcumin-loaded $\gamma$-cyclodextrin liposomal nanoparticles as delivery vehicles for osteosarcoma. Nanomedicine: Nanotechnolog, Biology and Medicine, 8, 440-451.

Dias, D. A., Urban, S., \& Roessner, U. (2012). A Historical Overview of Natural Products in Drug Discovery. Metabolites, 2, 303-336.

Duan, X., Wu, F., Li, M., Yang, N., Wu, C., Jin, Y., Yang, J., Jin, Z., \& Xu, X. (2014). Naturally occurring angiotensin I-converting enzyme inhibitory peptide from a fertilized egg and its inhibitory mechanism. Journal of Agricultural and Food Chemistry, 62, 5500-5506.

Dwivedi, P., Khatik, R., Khandelwal, K., Taneja, I., Raju, K. S. R., Wahajuddin, Paliwal, S. K., Dwivedi, A. K., \& Mishra, P. R. (2014). Pharmacokinetics study of arteether loaded solid lipid nanoparticles: An improved oral bioavailability in rats. International Journal of Pharmaceutics, 466, 321-327.

Ensign, L. M., Henning, A., Schneider, C. S., Maisel, K., Wang, Y. Y., Porosoff, M. D., Cone, R., \& Hanes, J. (2013). Ex vivo characterization of particle transport in mucus secretions coating freshly excised mucosal tissues. Molecular Pharmaceutics, 10, 2176-2182.

Gao, X., He, C., Xiao, C., Zhuang, X., \& Chen, X. (2013). Biodegradable pH-responsive polyacrylic acid derivative hydrogels with tunable swelling behavior for oral delivery of insulin. Polymer, 54, 1786-1793.

Girgih, A. T., Myrie, S. B., Aluko, R. E., \& Jones, P. J. H. (2013). Is category 'A' status assigned to soy protein and coronary heart disease risk reduction health claim by the United States Food and Drug Administration still justifiable? Trends in Food Science \& Technology, 30, 121-132.

Gleeson, J. P., Heade, J., Ryan, S. M., \& Brayden, D. J. (2015). Stability, toxicity and intestinal permeation enhancement of two food-derived antihypertensive tripeptides, Ile-Pro-Pro and Leu-Lys-Pro. Peptides, 71, 1-7.

Gonzalez-Castejon, M., \& Rodriguez-Casado, A. (2011). Dietary phytochemicals and their potential effects on obesity: A review. Pharmacological Research, 64, 438-455. 
Gulotta, A., Saberi, A. H., Nicoli, M. C., \& McClements, D. J. (2014). Nanoemulsion-based delivery systems for polyunsaturated (omega-3) oils: formation using a spontaneous emulsification method. Journal of Agricultural and Food Chemistry, 62, 1720-1725.

Guri, A., Gulseren, I., \& Corredig, M. (2013). Utilization of solid lipid nanoparticles for enhanced delivery of curcumin in cocultures of HT29-MTX and Caco-2 cells. Food and Function, 4, 1410-1419.

Helgason, T., Awad, T. S., Kristbergsson, K., Decker, E. A., McClements, D. J., \& Weiss, J. (2009). Impact of surfactant properties on oxidative stability of beta-carotene encapsulated within solid lipid nanoparticles. Journal of Agricultural and Food Chemistry, 57, 8033-8040.

Hosseini, S. M. H., Emam-Djomeh, Z., Sabatino, P., \& Van der Meeren, P. (2015). Nanocomplexes arising from protein-polysaccharide electrostatic interaction as a promising carrier for nutraceutical compounds. Food Hydrocolloids, 50, 16-26.

Hu, B., Xie, M., Zhang, C., \& Zeng, X. (2014). Genipin-Structured Peptide-Polysaccharide Nanoparticles with Significantly Improved Resistance to Harsh Gastrointestinal Environments and Their Potential for Oral Delivery of Polyphenols. Journal of Agricultural and Food Chemistry, 62, 12443-12452.

Huttunen, K. M., Raunio, H., \& Rautio, J. (2011). Prodrugs - from Serendipity to Rational Design. Pharmacological Reviews, 63, 750-771.

Kakkar, V., Singh, S., Singla, D., \& Kaur, I. P. (2011). Exploring solid lipid nanoparticles to enhance the oral bioavailability of curcumin. Molecular Nutrition and Food Research, 55, 495-503.

Karsdal, M. A., Riis, B. J., Mehta, N., Stern, W., Arbit, E., Christiansen, C., \& Henriksen, K. (2015). Lessons learned from the clinical development of oral peptides. British Journal of Clinical Pharmacology, 79, 720-732.

Karthikeyan, S., Rajendra Prasad, N., Ganamani, A., \& Balamurugan, E. (2013). Anticancer activity of resveratrol-loaded gelatin nanoparticles on NCI-H460 non-small cell lung cancer cells. Biomedicine \& Preventive Nutrition, 3, 64-73.

Kosińska, A., \& Andlauer, W. (2013). Modulation of tight junction integrity by food components. Food Research International, 54, 951-960.

Kovacs-Nolan, J., Zhang, H., Ibuki, M., Nakamori, T., Yoshiura, K., Turner, P. V., Matsui, T., \& Mine, Y. (2012). The PepT1-transportable soy tripeptide VPY reduces intestinal inflammation. Biochimica et Biophysica Acta (BBA) - General Subjects, 1820, 17531763.

Krug, S. M., Amasheh, M., Dittmann, I., I., C., Fromm, M., \& Amasheh, S. (2013). Sodium caprate as an enhancer of macromolecule permeation across tricullular tight junctions of intestinal cells. Biomaterials, 34, 275-282.

Larregieu, C. A., \& Benet, L. Z. (2014). Distinguishing between the Permeability Relationships with Absorption and Metabolism To Improve BCS and BDDCS Predictions in Early Drug Discovery. Molecular Pharmaceutics, 11, 1335-1344.

Laukoetter, M. G., Nava, P., \& Nusrat, A. (2008). Role of the intestinal barrier in inflammatory bowel disease. World Journal of Gastroenterology : WJG, 14, 401-407. 
Lee, J. K., Jeon, J.-K., \& Byun, H.-G. (2014). Antihypertensive effect of novel angiotensin I converting enzyme inhibitory peptide from chum salmon (Oncorhynchus keta) skin in spontaneously hypertensive rats. Journal of Functional Foods, 7, 381-389.

Leong, K. H., Chung, L. Y., Noordin, M. I., Onuki, Y., Morishita, M., \& Takayama, K. (2011). Lectin-functionalized carboxymethylated kappa-carrageenan microparticles for oral insulin delivery. Carbohydrate Polymers, 86, 555-565.

Lewis, A. L., \& Richard, J. (2015). Challenges in the delivery of peptide drugs: an industry perspective. Therapeutic Delivery, 6, 149-163.

Li, Y., Kim, J., Park, Y., \& McClements, D. J. (2012). Modulation of lipid digestibility using structured emulsion-based delivery systems: Comparison of in vivo and in vitro measurements. Food \& Function, 3, 528-536.

Li, Z., \& Gu, L. (2014). Fabrication of Self-Assembled (-)-Epigallocatechin Gallate (EGCG) Ovalbumin-Dextran Conjugate Nanoparticles and Their Transport across Monolayers of Human Intestinal Epithelial Caco-2 Cells. Journal of Agricultural and Food Chemistry, 62, 1301-1309.

Liang, H., Zhou, B., He, L., An, Y., Lin, L., Li, Y., Liu, S., Chen, Y., \& Li, B. (2015). Fabrication of zein/quaternized chitosan nanoparticles for the encapsulation and protection of curcumin. RSC Advances, 5, 13891-13900.

Lin, L., Yee, S. W., Kim, R. B., \& Giacomini, K. M. (2015). SLC transporters as therapeutic targets: emerging opportunities. Nature Reviews Drug Discovery, 14, 543-560.

Liu, J., Willför, S., \& Xu, C. (2015). A review of bioactive plant polysaccharides: Biological activities, functionalization, and biomedical applications. Bioactive Carbohydrates and Dietary Fibre, 5, 31-61.

Lotito, S. B., Zhang, W. J., Yang, C. S., Crozier, A., \& Frei, B. (2011). Metabolic conversion of dietary flavonoids alters their anti-inflammatory and antioxidant properties. Free Radical Biology and Medicine, 51, 454-463.

Lu, X., Gao, H., Li, C., Yang, Y. W., Wang, Y., Fan, Y., Wu, G., \& Ma, J. (2012). Polyelectrolyte complex nanoparticles of amino poly(glycerol methacrylate)s and insulin. International Journal of Pharmaceutics, 423, 195-201.

Maher, S., Duffy, B., Ryan, A., \& Brayden, D. J. (2014). Formulation strategies to improve oral peptide delivery. Pharmaceutical Patent Analyst, 3, 313-336.

Maki, K. C., Yurko-Mauro, K., Dicklin, M. R., Schild, A. L., \& Geohas, J. G. (2014). A new microalgal DHA-and EPA-containing oil lowers triacylglycerols in adults with mildto-moderate hypertriglyceridemia. Prostaglandins, Leukotrienes and Essential Fatty Acids, 91, 141-148.

Mannarino, M. R., Ministrini, S., \& Pirro, M. (2014). Nutraceuticals for the treatment of hypercholesterolemia. Eur J Intern Med, 25, 592-599.

Martin, D. A., \& Bolling, B. W. (2015). A review of the efficacy of dietary polyphenols in experimental models of inflammatory bowel diseases. Food and Function, 6, 17731786.

McCartney, F., Gleeson, J. P., \& Brayden, D. J. (2016). Safety concerns over the use of intestinal permeation enhancers: A mini-review. Tissue Barriers, In Press. 
McClements, D. J. (2013a). Nanoemulsion-based oral delivery systems for lipophilic bioactive components: nutraceuticals and pharmaceuticals. Therapeutic Delivery, 4 , 841-857.

McClements, D. J. (2013b). Utilizing food effects to overcome challenges in delivery of lipophilic bioactives: structural design of medical and functional foods. Expert Opinion on Drug Delivery, 10, 1621-1632.

McClements, D. J., Decker, E. A., Park, Y., \& Weiss, J. (2009). Structural design principles for delivery of bioactive components in nutraceuticals and functional foods. Crit Rev Food Sci Nutr, 49, 577-606.

McClements, D. J., Li, F., \& Xiao, H. (2015). The Nutraceutical Bioavailability Classification Scheme: Classifying Nutraceuticals According to Factors Limiting their Oral Bioavailability. Annual Review of Food Science and Technology, 6, 299-327.

McClements, D. J., \& Xiao, H. (2014). Excipient foods: designing food matrices that improve the oral bioavailability of pharmaceuticals and nutraceuticals. Food \& Function, 5, 1320-1333.

Melmed, S., Popovic, V., Bidlingmaier, M., Mercado, M., Lely, A. J. v. d., Biermasz, N., Bolanowski, M., Coculescu, M., Schopohl, J., Racz, K., Glaser, B., Goth, M., Greenman, Y., Trainer, P., Mezosi, E., Shimon, I., Giustina, A., Korbonits, M., Bronstein, M. D., Kleinberg, D., Teichman, S., Gliko-Kabir, I., Mamluk, R., Haviv, A., \& Strasburger, C. (2015). Safety and Efficacy of Oral Octreotide in Acromegaly: Results of a Multicenter Phase III Trial. The Journal of Clinical Endocrinology \& Metabolism, 100, 1699-1708.

Memvanga, P. B., Coco, R., \& Préat, V. (2013). An oral malaria therapy: curcumin-loaded lipid-based drug delivery systems combined with $\beta$-arteether. Journal of Controlled Release, 172, 904-913.

Menotti, A., \& Puddu, P. E. (2015). How the Seven Countries Study contributed to the definition and development of the Mediterranean diet concept: a 50-year journey. Nutrition, metabolism, and cardiovascular diseases, 25, 245-252.

Morishita, M., Morishita, I., Takayama, K., Machida, Y., \& Nagai, T. (1993). Site-dependent effect of aprotinin, sodium caprate, Na2EDTA and sodium glycocholate on intestinal absorption of insulin. Biological and Pharmaceutical Bulletin, 16, 68-72.

Müller, C., Leithner, K., Hauptstein, S., Hintzen, F., Salvenmoser, W., \& Bernkop-Schnürch, A. (2012). Preparation and characterization of mucus-penetrating papain/poly(acrylic acid) nanoparticles for oral drug delivery applications. Journal of Nanoparticle Research, 15, 1-13.

Müller, C., Perera, G., König, V., \& Bernkop-Schnürch, A. (2014). Development and in vivo evaluation of papain-functionalized nanoparticles. European journal of pharmaceutics and biopharmaceutics, 87, 125-131.

Mun, S., Kim, Y.-R., \& McClements, D. J. (2015). Control of $\beta$-carotene bioaccessibility using starch-based filled hydrogels. Food Chemistry, 173, 454-461.

Nakamura, Y., Yamamoto, N., Sakai, K., Okubo, A., Yamazaki, S., \& Takano, T. (1995). Purification and characterization of angiotensin I-converting enzyme inhibitors from sour milk. Journal of Dairy Science, 78, 777-783. 
Nui, Y., Ke, D., Yang, Q., Wang, X., Chen, Z., An, X., \& Shen, W. (2012). Temperaturedependent stability and DPPH scavenging activity of liposomal curcumin at $\mathrm{pH}$ 7.0. Food Chemistry, 135, 1377-1382.

Pan, M.-H., Lai, C.-S., Dushenkov, S., \& Ho, C.-T. (2009). Modulation of Inflammatory Genes by Natural Dietary Bioactive Compounds. Journal of Agricultural and Food Chemistry, 57, 4467-4477.

Pandita, D., Kumar, S., Poonia, N., \& Lather, V. (2014). Solid lipid nanoparticles enhance oral bioavailability of resveratrol, a natural polyphenol. Food Research International, 62, 1165-1174.

Pando, D., Gutiérrez, G., Coca, J., \& Pazos, C. (2013). Preparation and characterization of niosomes containing resveratrol. Journal of Food Engineering, 117, 227-234.

Patel, K. R., Scott, E., Brown, V. A., Gescher, A. J., Steward, W. P., \& Brown, K. (2011). Clinical trails of resveratrol. Annals of the New York Academy of Sciences, 1215, 161169.

Penalva, R., Esparza, I., Larraneta, E., Gonzalez-Navarro, C. J., Gamazo, C., \& Irache, J. M. (2015). Zein-Based Nanoparticles Improve the Oral Bioavailability of Resveratrol and Its Anti-inflammatory Effects in a Mouse Model of Endotoxic Shock. Journal of Agricultural and Food Chemistry, 63, 5603-5611.

Pereira de Sousa, I., Cattoz, B., Wilcox, M. D., Griffiths, P. C., Dalgliesh, R., Rogers, S., \& Bernkop-Schnurch, A. (2015). Nanoparticles decorated with proteolytic enzymes, a promising strategy to overcome the mucus barrier. European Journal of Pharmaceutical Sciences, In Press.

Petersen, S. B., Nielsen, L. G., Rahbek, U. L., Guldbrandt, M., \& Brayden, D. J. (2013). Colonic absorption of salmon calcitonin using tetradecyl maltoside (TDM) as a permeation enhancer. European Journal of Pharmaceutical Sciences, 48, 726-734.

Renukuntla, J., Vadlapudi, A. D., Patel, A., Boddu, S. H., \& Mitra, A. K. (2013). Approaches for enhancing oral bioavailability of peptides and proteins. International Journal of Pharmaceutics, 447, 75-93.

Ron, N., Zimet, P., Bargarum, J., \& Livney, Y. D. (2010). Beta-lactoglobulin-polysaccharide complexes as nanovehicles for hydrophobic nutraceuticals in non-fat foods and clear beverages. International Dairy Journal, 20, 686-693.

Ryan, S. M., McMorrow, J., Umerska, A., Patel, H. B., Kornerup, K. N., Tajber, L., Murphy, E. P., Perretti, M., Corrigan, O. I., \& Brayden, D. J. (2013). An intra-articular salmon calcitonin-based nanocomplex reduces experimental inflammatory arthritis. Journal of Controlled Release, 167, 120-129.

Sarika, P. R., Pavithran, A., \& James, N. R. (2015). Cationized gelatin/gum arabic polyelectrolyte complex: Study of electrostatic interactions. Food Hydrocolloids, 49, 176-182.

Shin, G. H., Chung, S. K., Kim, J. T., Joung, H. J., \& Park, H. J. (2013). Preparation of chitosan-coated nanoliposomes for improving the mucoadhesive property of curcumin using the ethanol injection method. Journal of Agricultural and Food Chemistry, 61, 11119-11126.

Sigurdsson, H. H., Kirch, J., \& Lehr, C.-M. (2013). Mucus as a barrier to lipophilic drugs. International Journal of Pharmaceutics, 453, 56-64. 
Skulas-Ray, A. C. (2015). Omega-3 fatty acids and inflammation: A perspective on the challenges of evaluating efficacy in clinical research. Prostaglandins and Other Lipid Mediators, 116-117, 104-111.

Stern, W., Mehta, N., \& Carl, S. (2013). Oral delivery of peptides by PeptelligenceTM technology. Drug Development and Delivery, 13, 38-42.

Sung, M.-R., Xiao, H., Decker, E. A., \& McClements, D. J. (2015). Fabrication, characterization and properties of filled hydrogel particles formed by the emulsiontemplate method. Journal of Food Engineering, 155, 16-21.

Szüts, A., \& Szabó-Révész, P. (2012). Sucrose esters as natural surfactants in drug delivery systems - A mini-review. International Journal of Pharmaceutics, 433, 1-9.

Takatsuka, S., Kitazawa, T., Morita, T., Horikiri, Y., \& Yoshino, H. (2006). Enhancement of intestinal absorption of poorly absorbed hydrophilic compounds by simultaneous use of mucolytic agent and non-ionic surfactant. European journal of pharmaceutics and biopharmaceutics, 62, 52-58.

Tan, C., Xue, J., Lou, X., Abbas, S., Guan, Y., Feng, B., Zhang, X., \& Xia, S. (2014). Liposomes as delivery systems for carotenoids: comparative studies of loading ability, storage stability and in vitro release. Food and Function, 5, 1232-1240.

Tavano, L., Muzzalupa, R., Picci, N., \& de Cindo, B. (2014). Co-encapsulation of antioxidants into niosomal carriers: Gastrointestinal release studies for nutraceutical applications. Colloids Surf B Biointerfaces, 114, 82-88.

Ting, Y., Chiou, Y.-S., Pan, M.-H., Ho, C.-T., \& Huang, Q. (2015). In vitro and in vivo anticancer activity of tangeretin against colorectal cancer was enhanced by emulsionbased delivery system. Journal of Functional Foods, 15, 264-273.

Turpeinen, A. M., Jarvenpaa, S., Kautiainen, H., Korpela, R., \& Vapaatalo, H. (2013). Antihypertensive effects of bioactive tripeptides - a random effects meta-analysis. Annals of Medicine, 45, 51-56.

Tuvia, S., Atsmon, J., Teichman, S. L., Katz, S., Salama, P., Pelled, D., Landau, I., Karmeli, I., Bidlingmaier, M., Strasburger, C. J., Kleinberg, D. L., Melmed, S., \& Mamluk, R. (2012). Oral Octreotide Absorption in Human Subjects: Comparable Pharmacokinetics to Parenteral Octreotide and Effective Growth Hormone Suppression. The Journal of Clinical Endocrinology \& Metabolism, 97, 2362-2369.

Tuvia, S., Pelled, D., Marom, K., Salama, P., Levin-Arama, M., Karmeli, I., Idelson, G., Landau, I., \& Mamluk, R. (2014). A Novel Suspension Formulation Enhances Intestinal Absorption of Macromolecules Via Transient and Reversible Transport Mechanisms. Pharmaceutical Research, 31, 2010-2021.

Uluata, S., McClements, D. J., \& Decker, E. A. (2015). How the multiple antioxidant properties of ascorbic acid affect lipid oxidation in oil-in-water emulsions. Journal of Agricultural and Food Chemistry, 63, 1819-1824.

Vigors, S., Sweeney, T., O'Shea, C. J., Browne, J. A., \& O'Doherty, J. V. (2014). Improvements in growth performance, bone mineral status and nutrient digestibility in pigs following the dietary inclusion of phytase are accompanied by modifications in intestinal nutrient transporter gene expression. British Journal of Nutrition, 112, 688697. 
Walker, R., Decker, E. A., \& McClements, D. J. (2015). Development of food-grade nanoemulsions and emulsions for delivery of omega-3 fatty acids: opportunities and obstacles in the food industry. Food \& Function, 6, 42-55.

Wallace, T., Weaver, C., Alexander, D., Boushey, C., Dawson-Hughes, B., Lappe, J., LeBoff, M., \& Looker, A. (2015). Calcium Plus Vitamin D Supplementation and Risk of Fractures: An Updated Meta-Analysis from NOF. The FASEB Journal, 29.

Wang, X., Maher, S., \& Brayden, D. J. (2010). Restoration of rat colonic epithelium after in situ intestinal instillations of the absorption promoter, sodium caprate. Therapeutic Delivery, 1, 75-82.

Xia, S., Tan, C., Zhang, Y., Abbas, S., Feng, B., \& Zhang, Z. (2015). Modulating effect of lipid bilayer-carotenoid interactions on the property of liposome encapsulation. Colloids Surf B Biointerfaces, 128, 172-180.

Xiao, J., Nian, S., \& Huang, Q. (2015). Assembly of kafirin/carboxymethyl chitosan nanoparticles to enhance the cellular uptake of curcumin. Food Hydrocolloids, 51, 166-175.

Xu, J. Y., Qin, L. Q., Wang, P. Y., Li, W., \& Chang, C. (2008). Effect of milk tripeptides on blood pressure: a meta-analysis of randomized controlled trials. Nutrition, 24, 933940.

Xue, J., \& Zhong, Q. (2014). Thyme oil nanoemulsions coemulsified by sodium caseinate and lecithin. Journal of Agricultural and Food Chemistry, 62, 9900-9907.

Yuan, S., Hollinger, M., Lachowicz-Scroggins, M. E., Kerr, S. C., Dunican, E. M., Daniel, B. M., Ghosh, S., Erzurum, S. C., Willard, B., Hazen, S. L., Huang, X., Carrington, S. D., Oscarson, S., \& Fahy, J. V. (2015). Oxidation increases mucin polymer crosslinks to stiffen airway mucus gels. Science Translational Medicine, 7, 276ra227276 ra227.

Zhang, Z., Gao, F., Bu, H., Xiao, J., \& Li, Y. (2012). Solid lipid nanoparticles loading candesartan cilexetil enhance oral bioavailability: in vitro characteristics and absorption mechanism in rats. Nanomedicine: Nanotechnolog, Biology and Medicine, 8, $740-747$.

Zheng, J., Li, Y., Song, M., Fang, X., Cao, Y., McClements, D. J., \& Xiao, H. (2014). Improving intracellular uptake of 5-demethyltangeretin by food grade nanoemulsions. Food Research International, 62, 98-103. 


\section{Figure Captions}

Fig. 1. Overview of food-derived bioactive compounds being investigated as nutraceuticals; Fatty acids (eicosapentaenoic acid (EPA) and docosahexaenoic acid (DHA)), bioactive peptides (Ile-Pro-Pro (IPP), and Leu-Lys-Pro, (LKP)), micronutrients (Vitamins B6, C and D3) and phytochemicals (the remainder). Adapted with permission (Pan, et al., 2009).

Fig. 2. Comparison of the Biopharmaceutics Classification System (BCS) and the recently proposed Nutraceutical Bioavailability Classification System (NuBACS) (Larregieu \& Benet, 2014; McClements, et al., 2015).

Fig. 3. Examples of food-based delivery systems currently being investigated for delivery of nutraceuticals. Lipid and surfactant-based vehicles including liposomes, niosomes, nanoemulsions and solid lipid nanoparticles (Error! Reference source not found.) are suitable for loading lipophilic bioactives (curcumin and resveratrol). Biopolymer-based vehicles including polyelectrolyte complexes, hydrogel particles and protein-polysaccharide structures are suitable for loading hydrophilic bioactives such (EGCG and ascorbic acid).

Fig. 4. $\mathrm{CoQ}_{10}$ plasma concentration after oral delivery in a nanoemulsion in rats. $\mathrm{CoQ}_{10}$ plasma AUC 26.14 ( $\mathrm{CoQ}_{10}$ nanoemulsion) > 15.38 (commercial oil mixture) > 12.79 (oily mixture $+\mathrm{CoQ}_{10}$ ) $>2.32$ (water and oily mixture). The commercial oil mixture consisted of soybean oil and $6 \% \mathrm{CoQ}_{10}$. Oily mixture consisted of same constituents of nanoemulsion without water sonication. Reproduced with permission (Belhaj, et al., 2012).

Fig. 5. Resveratrol plasma concentration significantly improved after oral delivery of resveratrol loaded zein-based nanoparticle $(\boldsymbol{\bullet})$ compared to resveratrol solution $(\bullet)$ and resveratrol suspension $(\boldsymbol{\Delta})$ in an endotoxic shock mouse model. The dose was $15 \mathrm{mg} / \mathrm{kg}$ and resveratrol plasma AUC was $5.17>0.60>$ ND respectively. Adapted with permission (Penalva, et al., 2015).

Fig. 6. The effect of PEs on nutraceutical compounds by improving mucodiffusion by mucolytic agents and improving permeability. Adapted with permission (Gleeson, et al., 2015). 


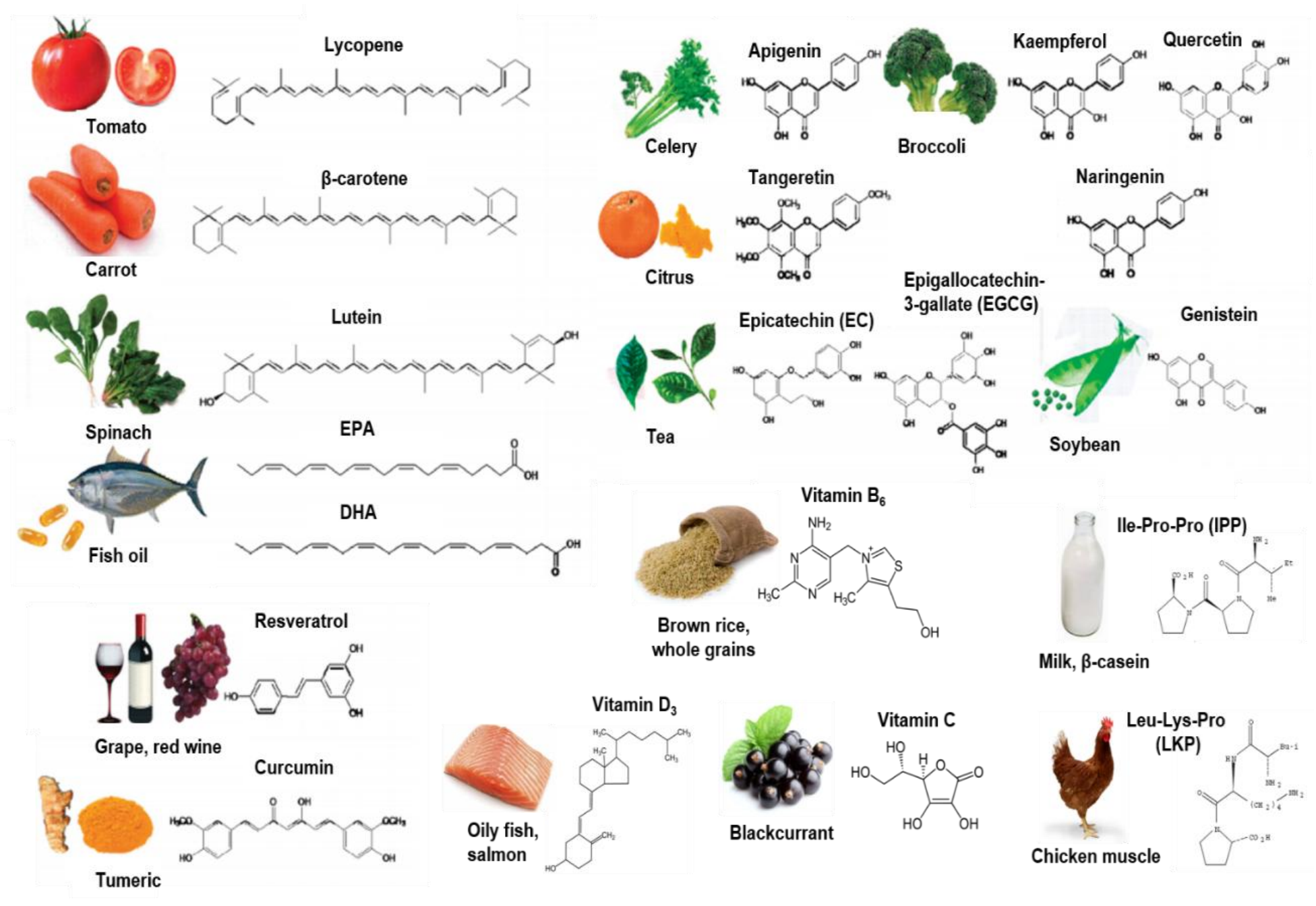

Fig. 1 

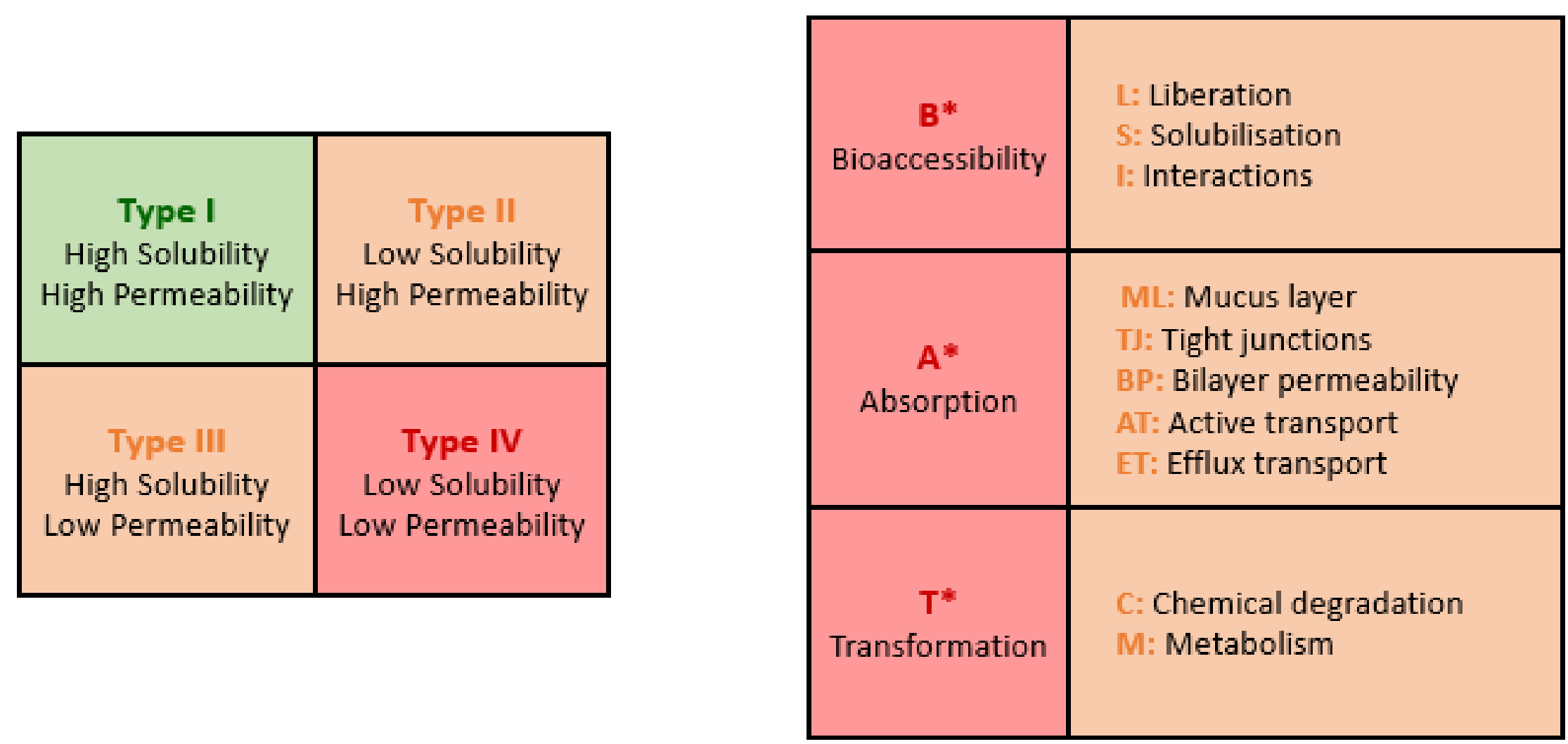

Fig. 2 


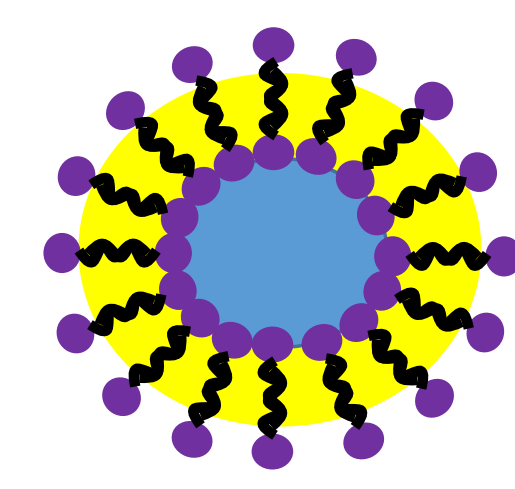

Liposome

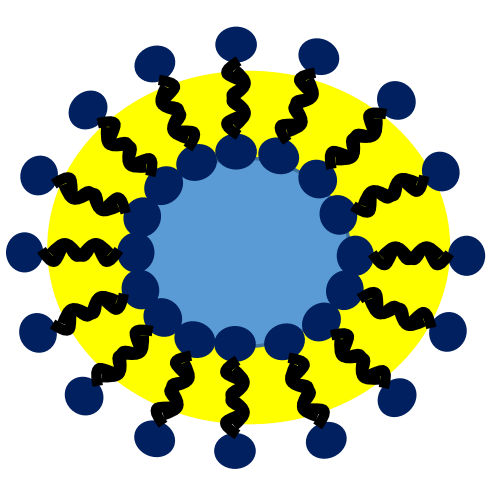

Niosome

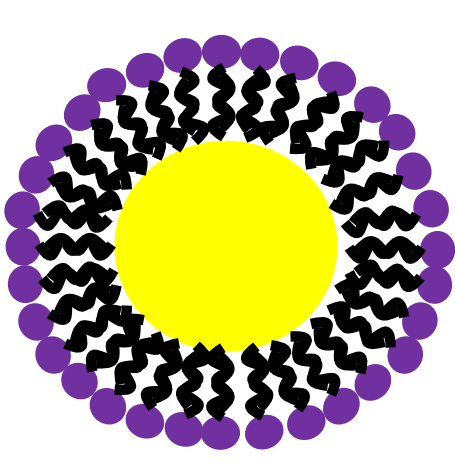

Nanoemulsion

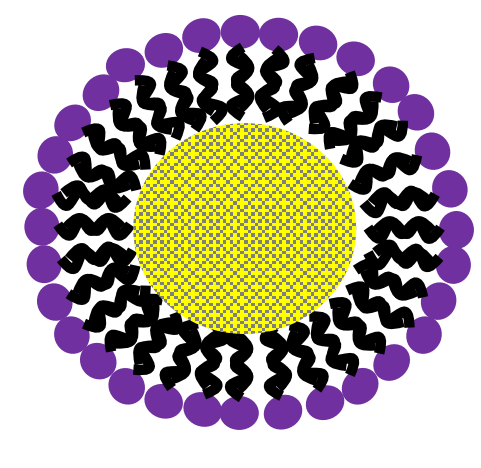

Solid Lipid

Nanoparticle

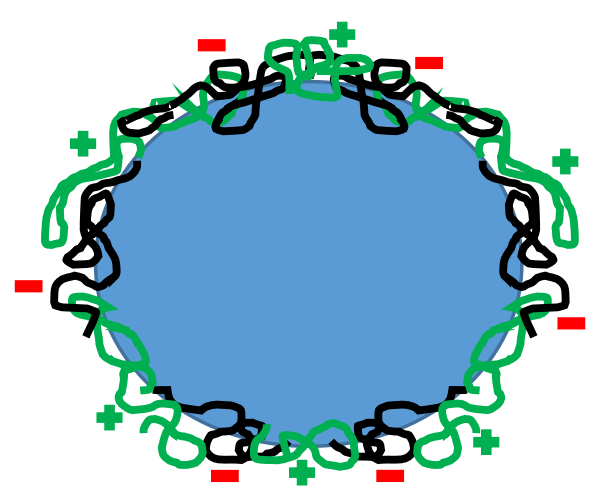

Polyelectrolyte Complexes

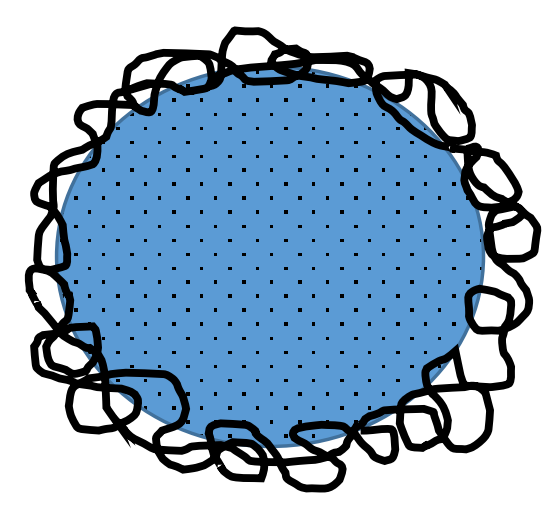

Hydrogel Particles

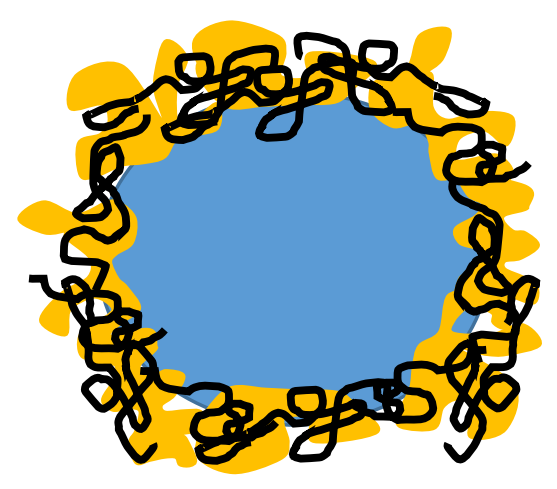

Protein-Polysaccharide Structure 


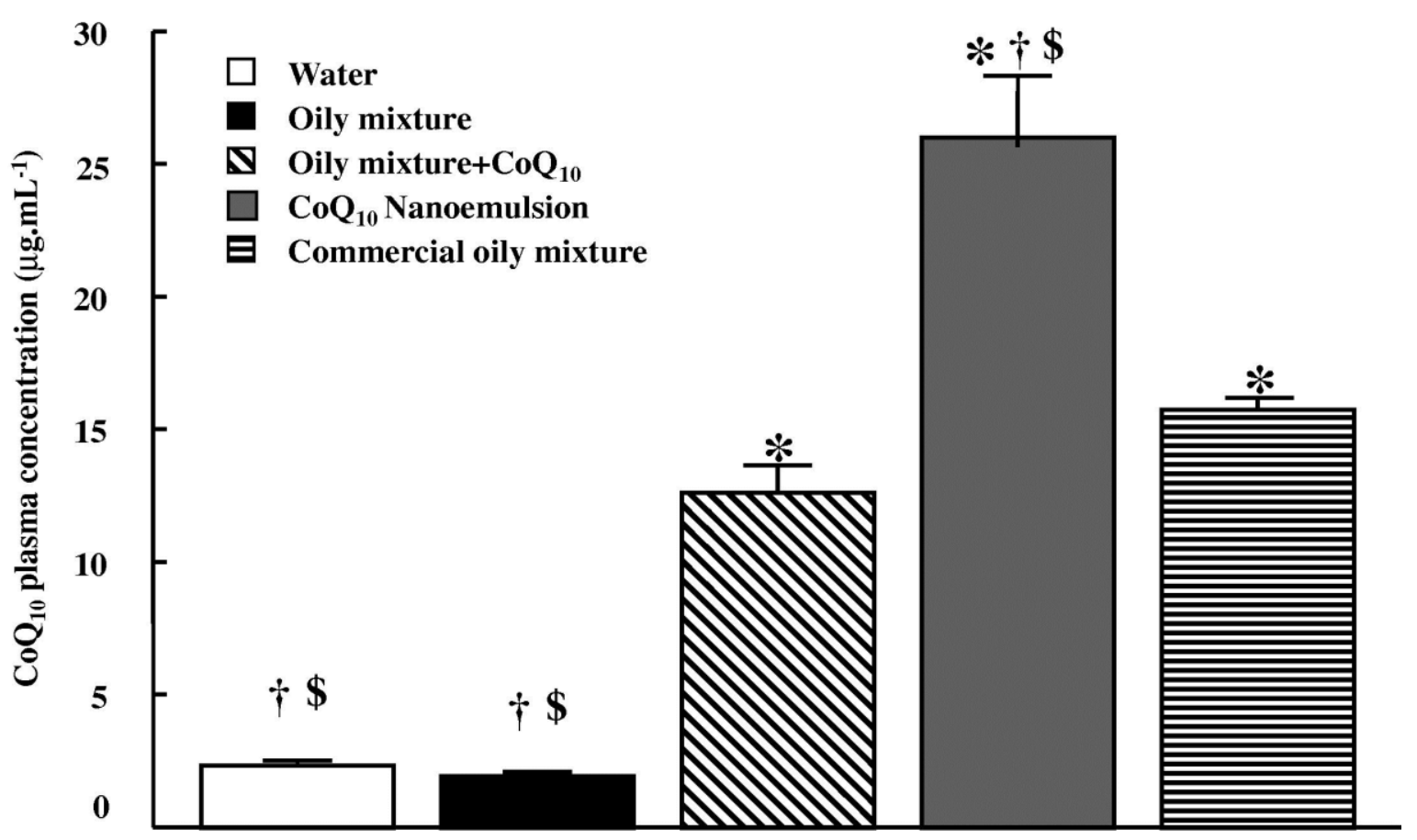

Fig. 4 


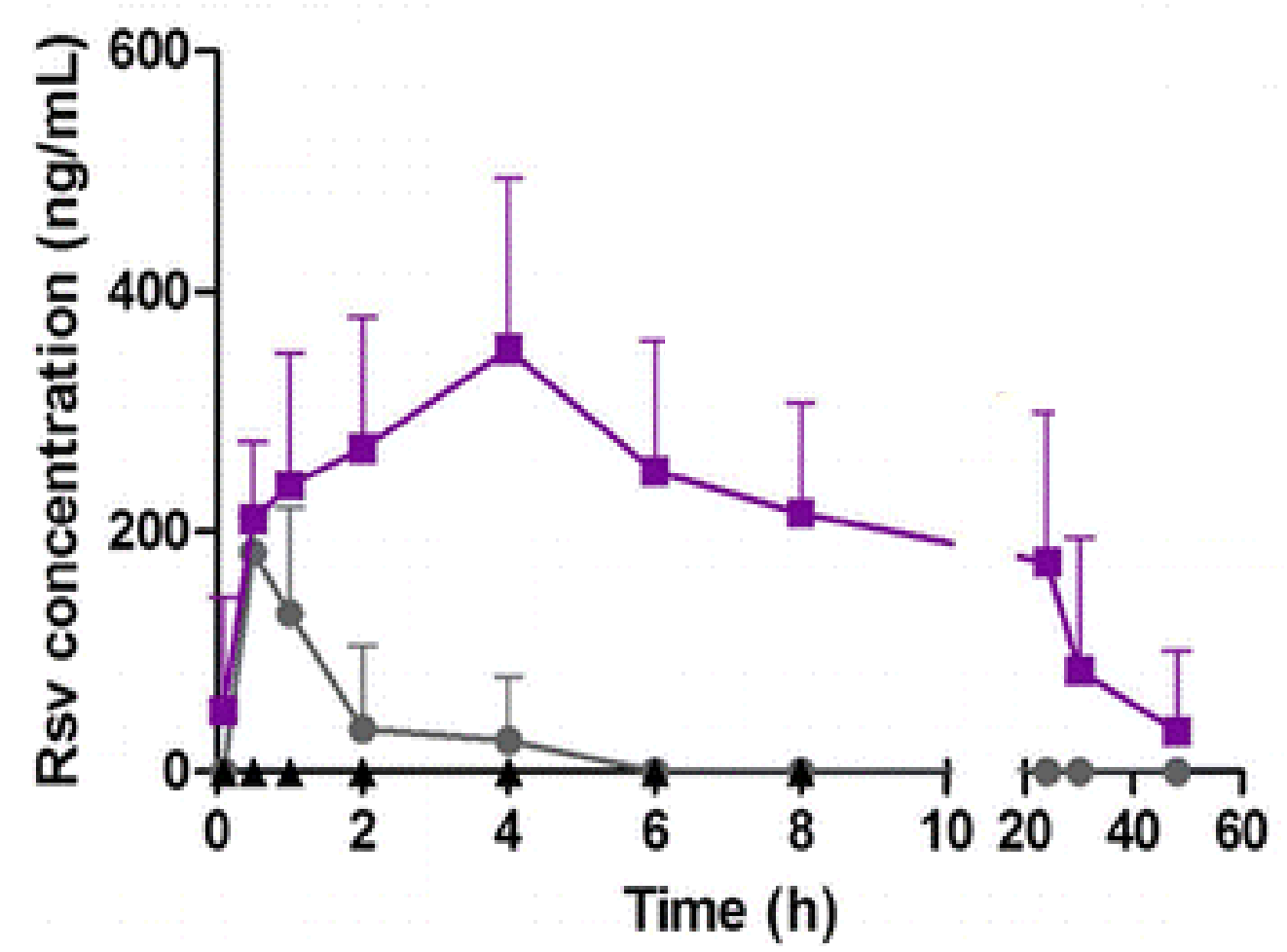

Fig. 5 


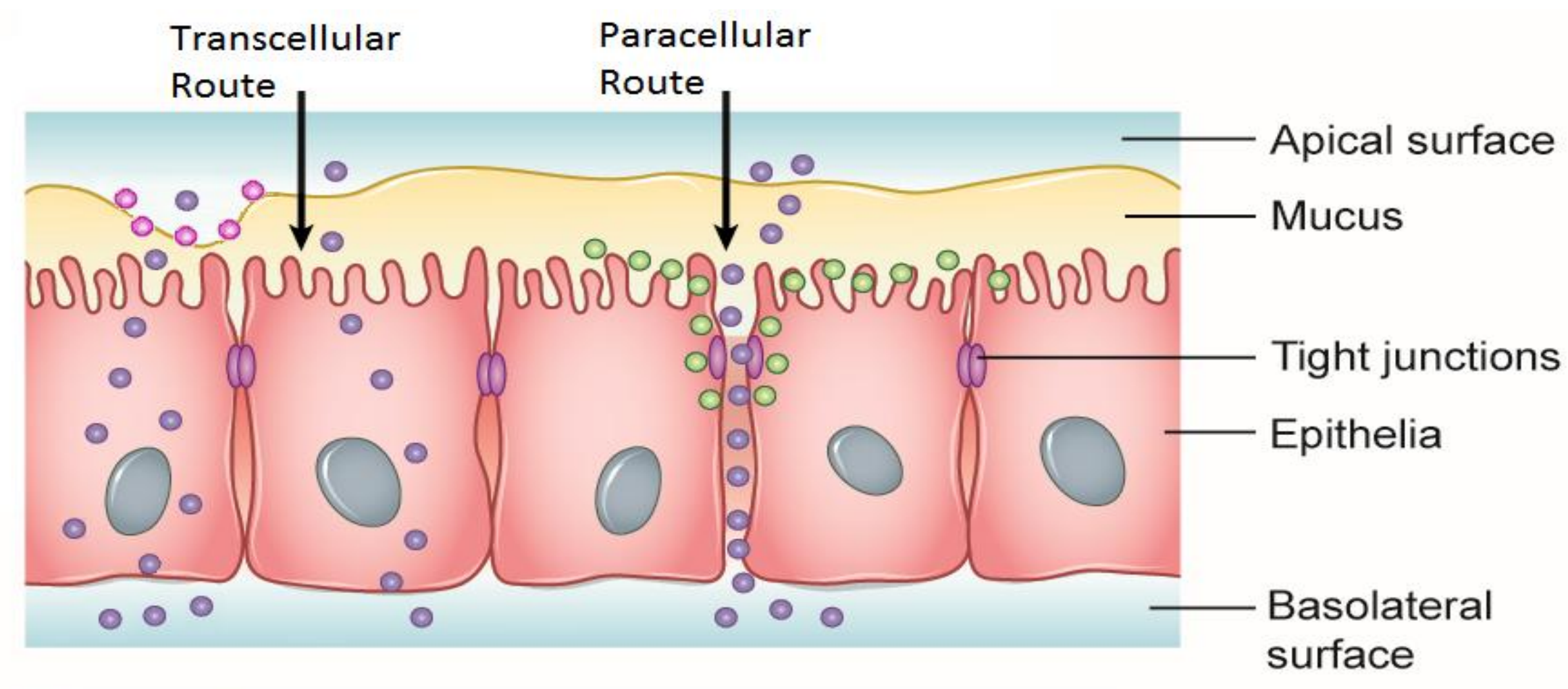

Permeation enhancer Nutraceutical compound Mucolytic agent 
Table 1. Overview of various types of nano-sized delivery vehicles created from food-based ingredients which have been formulated containing nutraceutical bioactives.

\begin{tabular}{|c|c|c|c|}
\hline Type & $\begin{array}{c}\text { Primary } \\
\text { constituent }\end{array}$ & $\begin{array}{c}\text { Food-based vehicle } \\
\text { (nanoparticle material) }\end{array}$ & $\begin{array}{l}\text { Nutraceutical payload } \\
\text { (loaded in nanoparticle) }\end{array}$ \\
\hline $\begin{array}{l}\text { Liposomes and } \\
\text { Niosomes }\end{array}$ & $\begin{array}{l}\text { Phospholipid or Non- } \\
\text { ionic surfactant }\end{array}$ & $\begin{array}{l}\text { Egg yolk phosphatidylcholine } \\
\text { (Memvanga, et al., 2013; Tan, et al., } \\
\text { 2014; Xia, et al., 2015); Sucrose } \\
\text { laurate (Pando, et al., 2013; Tavano, } \\
\text { et al., 2014) }\end{array}$ & $\begin{array}{l}\text { Carotenoids (Tan, et al., 2014); } \\
\text { Curcumin (Dhule, et al., 2012; } \\
\text { Memvanga, et al., 2013; Nui, et al., } \\
\text { 2012; Shin, et al., 2013); }\end{array}$ \\
\hline Nanoemulsions & Surfactant and oil & $\begin{array}{l}\text { Essential oils (Gulotta, Saberi, } \\
\text { Nicoli, \& McClements, 2014; Xue \& } \\
\text { Zhong, 2014); Medium chain } \\
\text { tryglyceride (Gulotta, et al., 2014; } \\
\text { Zheng, et al., 2014); Soybean } \\
\text { lecithin (Aditya, et al., 2013); } \beta- \\
\text { Lactoglobulin (Zheng, et al., 2014) }\end{array}$ & $\begin{array}{l}\text { Essential oils (Gulotta, et al., } \\
\text { 2014; Xue \& Zhong, 2014); 5-DT } \\
\text { (Zheng, et al., 2014); Curcumin } \\
\text { (Aditya, et al., 2013); Genistein } \\
\text { (Aditya, et al., 2013); omega-3 } \\
\text { FAs (Gulotta, et al., 2014); }\end{array}$ \\
\hline $\begin{array}{l}\text { Solid Lipid } \\
\text { Nanoparticles } \\
\text { (SLN) }\end{array}$ & $\begin{array}{l}\text { Semi- or fully } \\
\text { solidified lipid }\end{array}$ & $\begin{array}{l}\text { Soy lecithin (Guri, et al., 2013; } \\
\text { Kakkar, et al., 2011; Pandita, et al., } \\
\text { 2014); palmitic acid (Kakkar, et } \\
\text { al., 2011); stearic acid (Pandita, et } \\
\text { al., 2014); }\end{array}$ & $\begin{array}{l}\text { Curcumin (Guri, et al., 2013); } \beta \text { - } \\
\text { Carotene (Helgason, et al., 2009); } \\
\text { Resveratrol (Pandita, et al., 2014) }\end{array}$ \\
\hline $\begin{array}{l}\text { Polyelectrolyte } \\
\text { complexes } \\
\text { (PEC) }\end{array}$ & $\begin{array}{l}\text { Oppositely charged } \\
\text { biopolymers }\end{array}$ & $\begin{array}{l}\beta \text {-Lactoglobulin (Hosseini, } \\
\text { Emam-Djomeh, Sabatino, \& Van der } \\
\text { Meeren, 2015); sodium alginate } \\
\text { (Hosseini, et al., 2015); gelatin } \\
\text { (Karthikeyan, et al., 2013; Sarika, et } \\
\text { al., 2015); Arabic gum (Sarika, et } \\
\text { al., 2015) }\end{array}$ & $\begin{array}{l}\text { Curcumin (Hosseini, et al., 2015); } \\
\beta \text {-carotene (Hosseini, et al., 2015); } \\
\text { Resveratrol (Karthikeyan, et al., } \\
2013 \text { ) }\end{array}$ \\
\hline Hydrogels & $\begin{array}{lr}\text { Denatured proteins } \\
\text { or ionically } \\
\text { crosslinked }\end{array}$ & $\begin{array}{l}\text { Rice starch (Mun, et al., 2015); } \\
\text { caseinophosphopeptide (Hu, et } \\
\text { al., 2014); chitosan (Hu, et al., } \\
\text { 2014); Whey protein isolate }\end{array}$ & $\begin{array}{l}\beta \text {-Carotene (Mun, et al., 2015); } \\
\text { Epigallocatechin gallate } \\
(\text { EGCG) (Hu, et al., 2014); }\end{array}$ \\
\hline
\end{tabular}




\begin{tabular}{|c|c|c|c|}
\hline & polysaccharides & $\begin{array}{l}\text { (Sung, Xiao, Decker, \& McClements, } \\
\text { 2015); } \beta \text {-Lactoglobulin (Y. Li, et } \\
\text { al., 2012) }\end{array}$ & \\
\hline $\begin{array}{l}\text { Protein- } \\
\text { carbohydrate } \\
\text { (self-assembly } \\
\text { structures) }\end{array}$ & $\begin{array}{l}\text { Globular proteins } \\
\text { and ionic } \\
\text { polysaccharides }\end{array}$ & $\begin{array}{l}\beta \text {-Lactoglobulin (Ron, et al., } \\
\text { 2010); pectin (Ron, et al., 2010); } \\
\text { zein (Liang, et al., 2015); kafirin } \\
\text { (Xiao, et al., 2015); ovalbumin (Z. } \\
\text { Li \& Gu, 2014) }\end{array}$ & $\begin{array}{l}\text { Vitamin } D_{2} \text { (Ron, et al., 2010); } \\
\text { Curcumin (Liang, et al., 2015; } \\
\text { Xiao, et al., 2015); EGCG (Hu, et } \\
\text { al., 2014; Z. Li \& Gu, 2014) }\end{array}$ \\
\hline
\end{tabular}

